\title{
On Almost $\pi G \beta$ closed mapping and Contra $\pi G \beta$ closed mapping in Intuitionistic Fuzzy Topological Spaces
}

\author{
S. Jothimani ${ }^{1 *}$, T. Jenitha Premalatha ${ }^{2}$, \\ 1*Dept.of Mathematics, Govt. Arts College, Bharathiar University, Coimbatore, India. \\ ${ }^{2}$ Dept. of Mathematics, TIPS College of Arts and Science, Bharathiar University, Coimbatore, India. \\ *Corresponding Author: joel.jensi@gmail.com, Tel.: 9994163007.
}

Available online at: www.isroset.org

Accepted 17/Aug/2018, Online 30/Aug/2018

Abstract - In this paper we introduce intuitionistic fuzzy almost pi generalized beta closed mappings intuitionistic fuzzy contra pi generalized beta continuous mappings and intuitionistic fuzzy almost contra pi generalized beta continuous mappings.

Keywords-Intuitionistic fuzzy almost $\pi \mathrm{G} \beta$ continuous mappings, intuitionistic fuzzy contra $\pi \mathrm{G} \beta$ continuous mappings, intuitionistic fuzzy almost contra $\pi \mathrm{G} \beta$ continuous mappings and intuitionistic fuzzy contra $\pi \mathrm{G} \beta$ closed mappings.

\section{INTRODUCTION}

Zadeh [13] introduced fuzzy sets in 1965, and in 1968, Chang [2] introduced fuzzy topology. After the introduction of fuzzy set and fuzzy topology, the notion of intuitionistic fuzzy sets was introduced by

Atanassov [1] as a generalization of fuzzy sets. In 1997, Coker [3] introduced the concept of intuitionistic fuzzy topological spaces. In 2005, Young Bae Jun and Seok Zun Song [12] introduced Intuitionistic fuzzy beta continuous mappings in intuitionistic fuzzy topological spaces. S.Jothimani and T.Jenitha premalatha [7] introduced the notion of intuitionistic fuzzy $\pi$ generalized beta closed mappings and intuitionistic fuzzy $\pi$ generalized beta open mappings. In this paper we introduce intuitionistic fuzzy almost $\pi$ generalized beta closed mappings, intuitionistic fuzzy contra $\pi$ generalized $\beta$ continuous mappings, and intuitionistic fuzzy almost contra $\pi$ generalized $\beta$ continuous mappings. We investigate some of their properties.

\section{PRELIMINARIES}

Definition 2.1: [1] An intuitionistic fuzzy set(IFS in short) $A$ in $X$ is an object having the form $A=\{<x, \mu A(x)$, $v \mathrm{~A}(\mathrm{x})>/ \mathrm{X} \in \mathrm{X}\}$ where the functions $\mu \mathrm{A}: \mathrm{X} \rightarrow[0,1]$ and $v \mathrm{~A}:$ $X \rightarrow[0,1]$ denote the degree of membership (namely $\mu \mathrm{A}(\mathrm{x})$ ) and the degree of non -membership (namely $v \mathrm{~A}(\mathrm{x})$ ) of each element $\mathrm{x} \in \mathrm{X}$ to the set $\mathrm{A}$, respectively, and $0 \leq \mu \mathrm{A}$ (x) $+v A(x) \leq 1$ for each $x \in X$. Denote by $\operatorname{IFS}(X)$, the set of all intuitionistic fuzzy sets in $\mathrm{X}$.

Definition 2.2: [1] Let $A$ and $B$ be IFSs of the form $A=$ $\{\langle\mathrm{x}, \mu \mathrm{A}(\mathrm{x}), v \mathrm{~A}(\mathrm{x})\rangle / \mathrm{x} \in \mathrm{X}\}$ and $\mathrm{B}=\{\langle\mathrm{x}, \mu \mathrm{B}(\mathrm{x}), v \mathrm{~B}(\mathrm{x})\rangle /$ $\mathrm{x} \in \mathrm{X}\}$. Then

(a) $\mathrm{A} \subseteq \mathrm{B}$ if and only if $\mu \mathrm{A}(\mathrm{x}) \leq \mu \mathrm{B}$ ( $\mathrm{x})$ and $v \mathrm{~A}(\mathrm{x}) \geq v \mathrm{~B}(\mathrm{x})$ for all $\mathrm{x} \in \mathrm{X}$

(b) $\mathrm{A}=\mathrm{B}$ if and only if $\mathrm{A} \subseteq \mathrm{B}$ and $\mathrm{B} \subseteq \mathrm{A}$

(c) $\mathrm{A}^{\mathrm{c}}=\{\langle\mathrm{x}, v \mathrm{~A}(\mathrm{x}), \mu \mathrm{A}(\mathrm{x})\rangle / \mathrm{x} \in \mathrm{X}\}$

(d) $\mathrm{A} \cap \mathrm{B}=\{\langle\mathrm{x}, \mu \mathrm{A}(\mathrm{x}) \cap \mu \mathrm{B}(\mathrm{x}), v \mathrm{~A}(\mathrm{x}) \cup v \mathrm{~B}(\mathrm{x})>/ \mathrm{x} \in \mathrm{X}\}$

(e) $\mathrm{A} \cup \mathrm{B}=\{\langle\mathrm{x}, \mu \mathrm{A}(\mathrm{x}) \cup \mu \mathrm{B}(\mathrm{x}), v \mathrm{~A}(\mathrm{x}) \cap v \mathrm{~B}(\mathrm{x})\rangle / \mathrm{x} \in \mathrm{X}\}$

We shall use the notation $A=\langle x, \mu A, v A\rangle$ instead of $A=\langle$ $\mathrm{x}, \mu \mathrm{A}(\mathrm{x}), v \mathrm{~A}(\mathrm{x})\rangle / \mathrm{x} \in \mathrm{X}\}$.

The intuitionistic fuzzy sets $0 \sim=\{\langle\mathrm{x}, 0,1\rangle / \mathrm{x} \in \mathrm{X}\}$ and $1 \sim=$ $\{\langle\mathrm{x}, 1,0\rangle / \mathrm{x} \in \mathrm{X}\}$ are respectively the empty set and the whole set of $X$.

Definition 2.3: [11] The IFS $\mathrm{p}(\alpha, \beta)=\langle\mathrm{x}, \mathrm{p} \alpha, \mathrm{p} 1-\beta>$ where $\alpha \in(0,1], \beta \in[0,1)$ and $\alpha+\beta \leq 1$ is called an intuitionistic fuzzy point (IFP for short) in $\mathrm{X}$. 
Definition 2.4: [6] Let $\mathrm{p}(\alpha, \beta)$ be an IFP of an IFTS $(X, \tau)$. An IFS $A$ of $X$ is called an intuitionistic fuzzy neighborhood of $\mathrm{p}(\alpha, \beta)$ if there exists an IFOS B in X such that $\mathrm{p}(\alpha, \beta) \in \mathrm{B} \subseteq \mathrm{A}$.

Definition 2.5: [3] An intuitionistic fuzzy topology (IFT for short) on $\mathrm{X}$ is a family $\tau$ of IFSs in $\mathrm{X}$ satisfying the following axioms.

(i) $0 \sim, 1 \sim \in \tau$

(ii) $\mathrm{G} 1 \cap \mathrm{G} 2 \in \tau$ for any $\mathrm{G} 1, \mathrm{G} 2 \in \tau$

(iii) $\cup \mathrm{Gi} \in \tau$ for any family $\{\mathrm{Gi} / \mathrm{i} \in \mathrm{J}\} \in \tau$.

In this case the pair $(X, \tau)$ is called an intuitionistic fuzzy topological space (IFTS in short) and any IFS in $\tau$ are known as an intuitionistic fuzzy open set (IFOS in short) in X. The complement $\mathrm{A}^{\mathrm{C}}$ of an IFOS $\mathrm{A}$ in $\operatorname{IFTS}(\mathrm{X}, \tau)$ is called an intuitionistic fuzzy closed set (IFCS in short) in X.

Definition 2.6: [3] Let $(X, \tau)$ be an IFTS and $A=\langle x, \mu A$, $v A\rangle$ be an IFS in $X$. Then the intuitionistic fuzzy interior and intuitionistic fuzzy closure are defined by $\operatorname{int}(\mathrm{A})=\cup\{\mathrm{G} / \mathrm{G}$ is an IFOS in $X$ and $G \subseteq A\}$ and $\operatorname{cl}(A)=\cap\{K / K$ is an IF(i) $S$ in $X$ and $A \subseteq K$ \}. Note that for any $\operatorname{IFS} A$ in $(X, \tau)$, (me have $\operatorname{cl}\left(\mathrm{A}^{\mathrm{c}}\right)=[\operatorname{int}(\mathrm{A})]^{\mathrm{c}}$ and $\operatorname{int}\left(\mathrm{A}^{\mathrm{c}}\right)=[\operatorname{cl}(\mathrm{A})]^{\mathrm{c}}[11]$.

Definition 2.7: [9] An IFS $A=\langle x, \mu A, v A>$ in an IFTS $(X$, $\tau)$ is said to be an

(i) Intuitionistic fuzzy semi closed set (IFSCS in short) if $\operatorname{int}(\mathrm{cl}(\mathrm{A})) \subseteq \mathrm{A}$

(ii) Intuitionistic fuzzy pre closed set (IFPCS in short) if $\operatorname{cl}(\operatorname{int}(\mathrm{A})) \subseteq \mathrm{A}$

(iii) intuitionistic fuzzy $\alpha$ closed set (IF $\alpha C S$ in short) if $\operatorname{cl}(\operatorname{int}(\operatorname{cl}(\mathrm{A})) \subseteq \mathrm{A}$. These respective complements of the above IFCS $\mathrm{s}$ are called their respective IFOSs. The family of all IFSCSs, IFPCSs, and IF $\alpha$ CSs (respectively IFSOSs, IFPOSs and IF $\alpha O S s)$ of an $\operatorname{IFTS}(\mathrm{X}, \tau)$ are respectively denoted by $\operatorname{IFSC}(\mathrm{X}), \operatorname{IFPC}(\mathrm{X})$ and $\operatorname{IF} \alpha \mathrm{C}(\mathrm{X})$ (respectively $\operatorname{IFSO}(\mathrm{X}), \operatorname{IFPO}(\mathrm{X})$ and $\mathrm{IF} \alpha \mathrm{O}(\mathrm{X}))$.

Definition 2.8: [6] An IFS $A=\langle x, \mu A, v A\rangle$ in an $\operatorname{IFTS}(X, \tau)$ is said to be an intuitionistic fuzzy beta closed set (IF $\beta C S$ in short) if int $(\operatorname{cl}(\operatorname{int}(\mathrm{A}))) \subseteq \mathrm{A}$.

Definition 2.9:[10] An IFS A in an IFTS $(X, \tau)$ is said to be an intuitionistic fuzzy generalized beta closed set (IFG $\beta C S$ for short) if $\beta \operatorname{cl}(\mathrm{A}) \subseteq \mathrm{U}$ whenever $\mathrm{A} \subseteq \mathrm{U}$ and $\mathrm{U}$ is an IFOS in $(X, \tau)$.

Definition 2.10: [7] An IFS A in an IFTS $(X, \tau)$ is said to be an intuitionistic fuzzy $\pi$ generalized beta closed set (IFG $\beta C S$ for short) if $\beta \operatorname{cl}(\mathrm{A}) \subseteq \mathrm{U}$ whenever $\mathrm{A} \subseteq \mathrm{U}$ and $\mathrm{U}$ is an IF $\pi \mathrm{OS}$ in $(\mathrm{X}, \tau)$. The family of all IF $\pi \mathrm{G} \beta \mathrm{CS}$ s of an IFTS $(X, \tau)$ is denoted by $\operatorname{IF} \pi \mathrm{G} \beta C(X)$.
Definition 2.11: [6] Let $A$ be an IFS in an IFTS $(X, \tau)$. Then $\beta \operatorname{int}(A)=\cup\{G / G$ is an IF $\beta O S$ in $X$ and $G \subseteq A\} . \beta \operatorname{cl}(A)=\cap$ $\{\mathrm{K} / \mathrm{K}$ is an IF $\beta C S$ in $X$ and $A \subseteq K\}$. Note that for any IFS $A$ in $(X, \tau)$, we have $\beta \operatorname{cl}\left(\mathrm{A}^{\mathrm{c}}\right)=(\beta \operatorname{int}(\mathrm{A}))^{\mathrm{c}}$ and $\beta \operatorname{int}\left(\mathrm{A}^{\mathrm{c}}\right)=$ $(\beta \operatorname{cl}(\mathrm{A}))^{\mathrm{c}}[7]$.

Definition 2.12: [7] The complement $A^{c}$ of IF $\pi G \beta C S$ in an IFTS $(X, \tau)$ is called an IF $\pi$ G $\beta O S$ in $X$.

Definition 2.13: [6] Let $\mathrm{f}$ be a mapping from an $\operatorname{IFTS}(\mathrm{X}, \tau)$ into an IFTS $(\mathrm{Y}, \sigma)$.Then $\mathrm{f}$ is said to be an intuitionistic fuzzy closed mapping ((IFCM) for short) if $\mathrm{f}(\mathrm{A})$ is $\operatorname{IFC}(\mathrm{X})$ in $Y$, for each ICS B in X.

Definition 2.14: [9] Let a mapping $f:(X, \tau) \rightarrow(Y, \sigma)$ Then $f$ is said to be an

(i) Intuitionistic fuzzy semi continuous mapping if $\mathrm{f}^{-1}(\mathrm{~B})$ $\in \operatorname{IFSO}(\mathrm{X})$ for every $\mathrm{B} \in \sigma$.

(ii) Intuitionistic fuzzy $\alpha$-continuous mapping if $\mathrm{f}^{-1}(\mathrm{~B}) \in \mathrm{IF} \alpha \mathrm{O}(\mathrm{X})$ for every $\mathrm{B} \in \sigma$.

(iii) Intuitionistic fuzzy pre continuous mapping if $\mathrm{f}^{-1}(\mathrm{~B})$ $\in \mathrm{IFPO}(\mathrm{X})$ for every $\mathrm{B} \in \sigma$.

(iv) Intuitionistic fuzzy $\beta$ continuous mapping if

$\mathrm{f}^{-1}(\mathrm{~B}) \in \operatorname{IF} \beta \mathrm{O}(\mathrm{X})$ for every $\mathrm{B} \in \sigma$.

Definition 2.15: [10] Let $\mathrm{f}:(\mathrm{X}, \tau) \rightarrow(\mathrm{Y}, \sigma)$ be a mapping. Then $f$ is said to be an intuitionistic fuzzy generalized $\beta$ continuous mapping (IFG $\beta C M$ ) if $\mathrm{f}^{-1}(\mathrm{~B}) \in \operatorname{IFG} \beta \mathrm{C}$ in $\mathrm{X}$ for every IFCS B in Y.

Definition 2.16: [7] Let $\mathrm{f}:(\mathrm{X}, \tau) \rightarrow(\mathrm{Y}, \sigma)$ be a mapping. Then $\mathrm{f}$ is said to be an intuitionistic fuzzy $\pi$ generalized $\beta$ continuous mapping (IF $\pi \mathrm{G} \beta \mathrm{CM}$ ) if $\mathrm{f}^{-1}(\mathrm{~B}) \in \mathrm{IF} \pi \mathrm{G} \beta \mathrm{C}$ in $\mathrm{X}$ for every IFCS B in Y.

Definition 2.17: [12] Let $\mathrm{f}$ be a mapping from an IFTS (X, $\tau)$ into an $\operatorname{IFTS}(\mathrm{Y}, \sigma)$. Then $\mathrm{f}$ is said to be intuitionistic fuzzy almost continuous (IFA continuous in short) if $\mathrm{f}^{-1}(\mathrm{~B})$ $\in \mathrm{IFC}(\mathrm{X})$ for every IFRCS B in $\mathrm{Y}$.

Definition 2.18: [11] Let $\mathrm{f}$ be a mapping from an IFTS (X, $\tau)$ into an $\operatorname{IFTS}(\mathrm{Y}, \sigma)$. Then $\mathrm{f}$ is said to be intuitionistic fuzzy almost $\pi \mathrm{G} \beta$ continuous (IFA $\pi \mathrm{G} \beta$ continuous in short) if $\mathrm{f}^{-1}(\mathrm{~B}) \in \operatorname{IF} \pi \mathrm{G} \beta \mathrm{C}(\mathrm{X})$ for every IFRCS B in $\mathrm{Y}$.

Definition 2.19: [6] Let $\mathrm{c}(\alpha, \beta)$ be an IFP in $(X, \tau)$. An IFSA of $\mathrm{X}$ is called an intuitionistic fuzzy beta neighborhood (IF $\beta N$ for short) of $c(\alpha, \beta)$ if there is an IF $\beta$ OS B in $X$ such that $\mathrm{c}(\alpha, \beta) \in \mathrm{B} \subseteq \mathrm{A}$. 
Definition 2.20: [7] A mapping $\mathrm{f}: \mathrm{X} \rightarrow \mathrm{Y}$ is said to be an intuitionistic fuzzy $\pi$ generalized beta closed mapping (IF $\pi \mathrm{G} \beta \mathrm{CM}$, for short) if $\mathrm{f}(\mathrm{A})$ is an IF $\pi \mathrm{G} \beta \mathrm{CS}$ in $\mathrm{Y}$ for every IFCS A in X.

Definition 2.21: [7] A mapping $f: X \rightarrow Y$ is said to be an intuitionistic fuzzy $\mathrm{M} \pi$ generalized beta closed mapping (IFM $\pi \mathrm{G} \beta \mathrm{CM}$, for short) if $\mathrm{f}(\mathrm{A})$ is an IF $\pi \mathrm{G} \beta \mathrm{CS}$ in $\mathrm{Y}$ for every $\mathrm{IF} \pi \mathrm{G} \beta \mathrm{CS}$ A in $\mathrm{X}$.

Definition 2.22: [8] A mapping $\mathrm{f}: \mathrm{X} \rightarrow \mathrm{Y}$ is said to be an intuitionistic fuzzy almost $\pi$ generalized beta continuous mapping (IFA $\pi \mathrm{G} \beta C M$, for short) if $\mathrm{f}^{-1}(\mathrm{~A})$ is an IF $\pi \mathrm{G} \beta \mathrm{CS}$ in $\mathrm{X}$ for every IFRCS A in $\mathrm{Y}$.

Definition 2.23: [5] Two IFSs A and B are said to be $q$ coincident (AqB in short) if and only if there exists and element $\mathrm{x} \in \mathrm{X}$ such that $\mu \mathrm{A}(\mathrm{x})>v \mathrm{~B}(\mathrm{x})$ or $v \mathrm{~A}(\mathrm{x})<\mu \mathrm{B}(\mathrm{x})$.

Definition 2.24: [4] A mapping f: $(X, \tau) \rightarrow(Y, \sigma)$ is called an

i) intuitionistic fuzzy contra continuous if $\mathrm{f}^{-1}(\mathrm{~B})$ is an IFCS in $\mathrm{X}$ for every IFOS B in Y [4]

ii) intuitionistic fuzzy contra beta continuous if $\mathrm{f}^{-1}(\mathrm{~B})$ is an IF $\beta C S$ in $\mathrm{X}$ for every IFOS B in Y.[4]

iii) intuitionistic fuzzy contra $\pi \mathrm{G} \beta$ continuous if

$\mathrm{f}^{-1}(\mathrm{~B})$ is an IF $\pi \mathrm{G} \beta C$ CS in $\mathrm{X}$ for every IFOS B in Y.[8]

\section{INTUITIONISTIC FUZZY ALMOST $\pi$ G $\beta$ CLOSED MAPPINGS}

In this section we have introduced intuitionistic fuzzy almost $\pi \mathrm{G} \beta$ open mappings. We have investigated some of its properties.

Definition 3.1: A map f: $X \rightarrow Y$ is called an intuitionistic fuzzy almost $\pi$ generalized beta closed mapping (IFA $\pi \mathrm{G} \beta \mathrm{CM}$ for short) if $\mathrm{f}(\mathrm{A})$ is an IF $\pi \mathrm{G} \beta \mathrm{CS}$ in $\mathrm{Y}$ for each IFRCS A in X.

Example 3.2: Let $\mathrm{X}=\{\mathrm{a}, \mathrm{b}\}, \mathrm{Y}=\{\mathrm{u}, \mathrm{v}\}$ and $\mathrm{G} 1=$ $\langle\mathrm{x},(0.4 \mathrm{a}, 0.3 \mathrm{~b}),(0.5 \mathrm{a}, 0.6 \mathrm{~b})\rangle, \mathrm{G}_{2}=\langle\mathrm{y},(0.2 \mathrm{u}, 0.3 \mathrm{v}),(0.8 \mathrm{u}$, $0.7 \mathrm{~V})\rangle$.Then $\tau=\left\{0 \sim, \mathrm{G}_{1}, 1 \sim\right\}$ and $\sigma=\left\{0_{\sim}, \mathrm{G} 2,1 \sim\right\}$ are IFTs on $\mathrm{X}$ and $\mathrm{Y}$ respectively. Define a mapping $\mathrm{f:}(\mathrm{X}, \tau) \rightarrow(\mathrm{Y}, \sigma)$ by $\mathrm{f}(\mathrm{a})=\mathrm{u}$ and $\mathrm{f}(\mathrm{b})=\mathrm{v}$. Then $\mathrm{f}$ is an IFA $\pi \mathrm{G} \beta C M$.
Definition 3.3: A map f: $X \rightarrow Y$ is called an intuitionistic fuzzy almost $\pi$ generalized $\beta$ open mapping (IFA $\pi \mathrm{G} \beta$ OM for short) if $f(A)$ is an IF $\pi G \beta O S$ in $Y$ for each IFROS $A$ in $\mathrm{X}$.

Theorem 3.4: Every IFCM is an IFA $\pi \mathrm{G} \beta \mathrm{CM}$ but not conversely.

Proof: Let $\mathrm{f}: \mathrm{X} \rightarrow \mathrm{Y}$ be an IFCM. Let $\mathrm{A}$ be an IFRCS in $\mathrm{X}$. Since every IFRCS is an IFCS, $A$ is an IFCS in X. Then $\mathrm{f}$ (A) is an IFCS in Y. Since every IFCS is an IF $\pi$ G $\beta C S$, $f(A)$ is an $\operatorname{IF} \pi \mathrm{G} \beta \mathrm{CS}$ in $\mathrm{Y}$. Hence $\mathrm{f}$ is an IFA $\pi \mathrm{G} \beta \mathrm{CM}$.

Example 3.5: In Example $3.2 \mathrm{f}$ is an IFA $\pi \mathrm{G} \beta \mathrm{CM}$ but not an IFCM since $\mathrm{G}_{1}{ }^{\mathrm{c}}=\langle\mathrm{x},(0.5 \mathrm{a}, 0.6 \mathrm{~b}),(0.4 \mathrm{a}, 0.3 \mathrm{~b})\rangle$ is an IFCS in $\mathrm{X}$ but $\mathrm{f}\left(\mathrm{G}_{1}{ }^{\mathrm{c}}\right)=\langle\mathrm{y},(0.5 \mathrm{u}, 0.6 \mathrm{v}),(0.4 \mathrm{u}, 0.3 \mathrm{v})\rangle$ is not an IFCS in $\mathrm{Y}$, since $\mathrm{cl}\left(\mathrm{f}\left(\mathrm{G}_{1}{ }^{\mathrm{c}}\right)\right)=\mathrm{G}_{2}{ }^{\mathrm{c}} \not \subset \mathrm{f}\left(\mathrm{G}_{1}{ }^{\mathrm{c}}\right)$.

Theorem 3.6: Every IFSCM is an IFA $\pi \mathrm{G} \beta C M$ but not conversely.

Proof: Let $\mathrm{f}: \mathrm{X} \rightarrow \mathrm{Y}$ be an IFSCM. Let $\mathrm{A}$ be an IFRCS in $\mathrm{X}$. Since every IFRCS is an IFCS, $A$ is an IFCS in $X$. Then $\mathrm{f}$ (A) is an IFSCS in Y. Since every IFSCS is an IF $\pi$ G $\beta C S$, $f$ (A) is an IF $\pi \mathrm{G} \beta C$ S in $\mathrm{Y}$. Hence $\mathrm{f}$ is an IFA $\pi \mathrm{G} \beta C \mathrm{CM}$.

Example 3.7: Let $\mathrm{X}=\{\mathrm{a}, \mathrm{b}\}, \mathrm{Y}=\{\mathrm{u}, \mathrm{v}\}$ and $\mathrm{G} 1=$ $\langle\mathrm{x},(0.4 \mathrm{a}, 0.3 \mathrm{~b}),(0.5 \mathrm{a}, 0.6 \mathrm{~b})\rangle, \mathrm{G} 2=\langle\mathrm{y},(0.5 \mathrm{u}, 0.4 \mathrm{v}),(0.2 \mathrm{u}$, $0.3 \mathrm{v})\rangle$. Then $\tau=\{0 \sim, \mathrm{G} 1,1 \sim\}$ and $\sigma=\{0 \sim, \mathrm{G} 2,1 \sim\}$ are IFTs on $\mathrm{X}$ and $\mathrm{Y}$ respectively. Define a mapping $\mathrm{f}:(\mathrm{X}, \tau) \rightarrow(\mathrm{Y}, \sigma)$ by $\mathrm{f}(\mathrm{a})=\mathrm{u}$ and $\mathrm{f}(\mathrm{b})=\mathrm{v}$. Then $\mathrm{f}$ is an IFA $\pi \mathrm{G} \beta \mathrm{CM}$ but not an IFSCM, since $\mathrm{G}^{\mathrm{C}}{ }^{\mathrm{C}}=\left\langle\mathrm{x},(0.5 \mathrm{a}, 0.6 \mathrm{~b}),\left(0.4_{\mathrm{u}}, 0.3 \mathrm{~b}\right)\right\rangle$ is an IFCS in $X$ but $f\left(G_{1}{ }^{c}\right)=\langle y,(0.5 u, 0.6 v),(0.4 u, 0.3 v)\rangle$ is not an IFSCS in $\mathrm{Y}$, since $\operatorname{int}\left(\mathrm{cl}\left(\mathrm{f}\left(\mathrm{G}_{1}{ }^{\mathrm{c}}\right)\right)\right)=1 \sim \not \subset \mathrm{f}\left(\mathrm{G}_{1}^{\mathrm{c}}\right)$.

Theorem 3.8: Every IF $\alpha \mathrm{CM}$ is an IFA $\pi \mathrm{G} \beta C \mathrm{C}$ but not conversely.

Proof: Let $\mathrm{f}: \mathrm{X} \rightarrow \mathrm{Y}$ be an IFaCM. Let $\mathrm{A}$ be an IFRCS in $\mathrm{X}$. Since every IFRCS is an IFCS, $A$ is an IFCS in $\mathrm{X}$. Then $\mathrm{f}$ (A) is an IF $\alpha \mathrm{CS}$ in $\mathrm{Y}$. Since every IF $\alpha \mathrm{CS}$ is an IF $\pi \mathrm{G} \beta \mathrm{CS}$, $\mathrm{f}$ (A) is an IF $\pi \mathrm{G} \beta C$ S in $\mathrm{Y}$. Hence $\mathrm{f}$ is an IFA $\pi \mathrm{G} \beta C \mathrm{CM}$.

Example 3.9: In Example 3.2, $\mathrm{f}$ is an IFA $\pi \mathrm{G} \beta \mathrm{CM}$ but not an $\mathrm{IF} \alpha \mathrm{CM}$ since $\mathrm{G}^{\mathrm{C}}=\langle\mathrm{x},(0.5 \mathrm{a}, 0.6 \mathrm{~b}),(0.4 \mathrm{u}, 0.3 \mathrm{~b})\rangle$ is an 
IFCS in $\mathrm{X}$, but $\mathrm{f}\left(\mathrm{G} 1^{\mathrm{C}}\right)=\langle\mathrm{y},(0.5 \mathrm{u}, 0.6 \mathrm{v}),(0.4 \mathrm{u}, 0.3 \mathrm{v})\rangle$ is not an IF $\alpha \mathrm{CS}$ in $\mathrm{Y}$, since $\operatorname{cl}\left(\operatorname{int}\left(\mathrm{f}\left(\mathrm{Gl}^{\mathrm{C}}\right)\right)\right)=1 \not \subset \mathrm{f}\left(\mathrm{G1}^{\mathrm{C}}\right)$.

Theorem 3.10: Every IFPCM is an IFA $\pi \mathrm{G} \beta C M$ but not conversely.

Proof: Let $\mathrm{f}: \mathrm{X} \rightarrow \mathrm{Y}$ be an IFPCM. Let A be an IFRCS in $\mathrm{X}$. Since every IFRCS is an IFCS, A is an IFCS in $X$ Then $\mathrm{f}(\mathrm{A})$ is an IFPCS in Y. Since every IFPCS is an IF $\pi \mathrm{G} \beta C S$, $\mathrm{f}(\mathrm{A})$ is an $\operatorname{IF} \pi \mathrm{G} \beta C$ S in $\mathrm{Y}$. Hence $\mathrm{f}$ is an IFA $\pi \mathrm{G} \beta \mathrm{CM}$.

Example 3.11: In Example $3.2 \mathrm{f}$ is an IFA $\pi \mathrm{G} \beta \mathrm{CM}$ but not an IFPCM, since $G 1^{c}=\langle x,(0.5 a, 0.6 b),(0.4 a, 0.3 b)\rangle$ is an IFCS in $\mathrm{X}$ but $\mathrm{f}\left(\mathrm{G1}^{\mathrm{c}}\right)=\langle\mathrm{y},(0.5 \mathrm{u}, 0.6 \mathrm{v}),(0.4 \mathrm{u}, 0.3 \mathrm{v})\rangle$ is not an IFPCS in $\mathrm{Y}$, since $\operatorname{cl}\left(\operatorname{int}\left(\mathrm{f}\left(\mathrm{G} 1^{\mathrm{c}}\right)\right)\right)=\mathrm{G} 2^{\mathrm{c}} \not \subset \mathrm{f}\left(\mathrm{G} 1^{\mathrm{c}}\right)$.

Theorem 3.12: Every IFG $\beta C M$ is an IFA $\pi \mathrm{G} \beta C M$ but not conversely.

Proof: Let $f: X \rightarrow Y$ be an IFGßCM. Let A be an IFRCS in $X$. Since every IFRCS is an IFCS, A is an IFCS in $X$ Then $\mathrm{f}$ (A) is an IF $\pi \mathrm{G} \beta C$ S in $\mathrm{Y}$. Hence $\mathrm{f}$ is an IFA $\pi \mathrm{G} \beta \mathrm{CM}$.

Example3.13: Let $\mathrm{X}=\{\mathrm{a}, \mathrm{b}\}, \mathrm{Y}=\{\mathrm{u}, \mathrm{v}\}$ and $\mathrm{G} 1=$ $\langle\mathrm{x},(0.1 \mathrm{a}, 0.1 \mathrm{~b}),(0.4 \mathrm{a}, 0.4 \mathrm{~b})\rangle, \quad \mathrm{G} 2=\langle\mathrm{x},(0.2 \mathrm{a}, 0 \mathrm{~b}),(0.5 \mathrm{a}, 0.5 \mathrm{~b})\rangle$, $\mathrm{G} 3=\langle\mathrm{y},(0.5 \mathrm{u}, 0.6 \mathrm{v}),(0.2 \mathrm{u}, 0 \mathrm{v})\rangle$ and $\mathrm{G} 4=\langle\mathrm{y},(0.4 \mathrm{u}, 0.1 \mathrm{v})$, $(0.2 \mathrm{u}, 0.1 \mathrm{v})\rangle$. Then $\tau=\{0 \sim, \mathrm{G} 1, \mathrm{G} 2,1 \sim\}$ and $\sigma=$ $\{0 \sim, G 3, G 4,1 \sim\}$ are IFTs on $X$ and Y respectively. Define a mapping $f:(X, \tau) \rightarrow(Y, \sigma)$ by $f(a)=u$ and $f(b)=v$. Then $f$ is an IFA $\pi \mathrm{G} \beta \mathrm{M}$ but not an IFG $\beta \mathrm{CM}$, since $\mathrm{G}_{2}{ }^{\mathrm{C}}=$ $\langle\mathrm{x},(0.5 \mathrm{a}, 0.5 \mathrm{~b}),(0.2 \mathrm{a}, 0 \mathrm{~b})\rangle$ is an IFCS in $\mathrm{X}$ but $\mathrm{f}\left(\mathrm{G}_{2}{ }^{\mathrm{c}}\right)=\langle\mathrm{y},($ $0.5 \mathrm{u}, 0.5 \mathrm{v}),(0.2 \mathrm{u}, 0 \mathrm{v})\rangle$ is not an IF $\pi \mathrm{G} \beta C$ S in $\mathrm{Y}$, since $\mathrm{f}\left(\mathrm{G}_{2}{ }^{\mathrm{c}}\right)$ $\subseteq \mathrm{G} 3$ but $\beta \mathrm{cl}\left(\mathrm{f}\left(\mathrm{G}_{2}{ }^{\mathrm{c}}\right)=1 \sim \not \subset \mathrm{G} 3\right.$.

Theorem 3.14: Every IFACM is an IFA $\pi \mathrm{G} \beta C M$ but not conversely.

Proof: Let f: $(\mathrm{X}, \tau) \rightarrow(\mathrm{Y}, \sigma)$ be an IFACM. Let $\mathrm{A}$ be an IFRCS in $\mathrm{X}$. Since $\mathrm{f}$ is IFACM, $\mathrm{f}(\mathrm{A})$ is an IFCS in $\mathrm{Y}$. Since every IFCS is an IF $\pi \mathrm{G} \beta C$, $\mathrm{f}$ (A) is an IF $\pi \mathrm{G} \beta \mathrm{CS}$ in $\mathrm{Y}$ .Hence $\mathrm{f}$ is an IFA $\pi \mathrm{G} \beta \mathrm{CM}$.

Theorem 3.15: Let $f: X \rightarrow Y$ be a mapping. Then the following are equivalent

(i) $\mathrm{f}$ is an IFA $\pi \mathrm{G} \beta O M$ (ii) $\mathrm{f}$ is an IFA $\pi \mathrm{G} \beta \mathrm{CM}$.

Proof: Straightforward

Theorem3.16 A bijective mapping $\mathrm{f}: \mathrm{X} \rightarrow \mathrm{Y}$ is an IFA $\pi \mathrm{G} \beta$ closed mapping if and only if the image of each IFROS in $\mathrm{X}$ is an IF $\pi \mathrm{G} \beta O \mathrm{OS}$ in $\mathrm{Y}$.

Proof Necessity: Let A be an IFROS in X. This implies $A^{c}$ is IFRCS in $X$. Since $f$ is an IFA $\pi G \beta$ closed mapping, $f\left(A^{c}\right)$ is an $\operatorname{IF} \pi \mathrm{G} \beta C S$ in $Y$. Since $f\left(A^{c}\right)=(f(A))^{c}, f(A)$ is an $\mathrm{IF} \pi \mathrm{G} \beta \mathrm{OS}$ in $\mathrm{Y}$.

Sufficiency: Let A be an IFRCS in X. This implies $A^{c}$ is an IFROS in $\mathrm{X}$. By hypothesis, $\mathrm{f}\left(\mathrm{A}^{\mathrm{c}}\right)$ is an $\mathrm{IF} \pi \mathrm{G} \beta O \mathrm{OS}$ in $\mathrm{Y}$. Since $f\left(A^{c}\right)=(f(A))^{c}, f(A)$ is an IF $\pi G \beta C S$ in $Y$. Hence $f$ is an IFA $\pi \mathrm{G} \beta$ closed mapping.

Theorem3.17 Let $f:(X, \tau) \rightarrow(Y, \sigma)$ be an IFA $\pi \mathrm{G} \beta$ closed mapping. Then $\mathrm{f}$ is an IFA closed mapping if $\mathrm{Y}$ is an IF $\pi \beta T 1 / 2$ space.

Proof: Let $A$ be an IFRCS in X. Then $\mathrm{f}(\mathrm{A})$ is an IF $\pi \mathrm{G} \beta \mathrm{CS}$ in $\mathrm{Y}$, by hypothesis. Since $\mathrm{Y}$ is an IF $\pi \beta T 1 / 2$ space, $\mathrm{f}(\mathrm{A})$ is an IFCS in $Y$. Hence $f$ is an IFA closed mapping.

Theorem3.18: Let $\mathrm{f}: \mathrm{X} \rightarrow \mathrm{Y}$ be a mapping where $\mathrm{Y}$ is an IF $\pi \beta \mathrm{T}_{1 / 2}$ space. Then the following are equivalent:

(i) $\mathrm{f}$ is an IFA $\pi \mathrm{G} \beta \mathrm{CM}$

(ii) $\beta \mathrm{cl}(\mathrm{f}(\mathrm{A})) \subseteq \mathrm{f}(\mathrm{cl}(\mathrm{A}))$ for every IFßOS A in $\mathrm{X}$

(iii) $\beta \mathrm{cl}(\mathrm{f}(\mathrm{A})) \subseteq \mathrm{f}(\mathrm{cl}(\mathrm{A}))$ for every IFSOS $\mathrm{A}$ in $\mathrm{X}$.

$f(A) \subseteq \beta \operatorname{int}(f(\operatorname{int}(\operatorname{cl}(A))))$ for every IFPOS A in $X$.

Proof: (i) $\Rightarrow$ (ii) Let $\mathrm{A}$ be an IFßOS in $\mathrm{X}$.Then $\operatorname{cl}(\mathrm{A})$ is an IFRCS in X. By hypothesis $f(A)$ is an IF $\pi \mathrm{G} \beta C S$ in $Y$ and hence is an IF $\beta C S$ in $Y$, since $Y$ is an IF $\pi \beta T 1 / 2$ space.This implies $\beta \mathrm{cl}(\mathrm{f}(\mathrm{cl}(\mathrm{A})))=\mathrm{f}(\mathrm{cl}(\mathrm{A}))$.

Now $\quad \beta \operatorname{cl}(f(A)) \quad \subseteq \beta \mathrm{cl}(\mathrm{f}(\operatorname{cl}(\mathrm{A})))=\quad \mathrm{f}(\mathrm{cl}(\mathrm{A}))$. Thus $\beta \operatorname{cl}(\mathrm{f}(\mathrm{A})) \subseteq \mathrm{f}(\mathrm{cl}(\mathrm{A}))$.

(ii) $\Rightarrow$ (iii) Since every IFSOS is an IF $\beta O S$, the proof directly follows.

(iii) $\Rightarrow$ (i) Let $A$ be an IFRCS in $X$. Then $A=\operatorname{cl}(\operatorname{int}(A)$ ). Therefore $\mathrm{A}$ is an IFSOS in X. By hypothesis, $\beta \mathrm{cl}(\mathrm{f}(\mathrm{A})) \subseteq$ $\mathrm{f}(\mathrm{cl}(\mathrm{A}))=\mathrm{f}(\mathrm{A}) \subseteq \beta \mathrm{cl}(\mathrm{f}(\mathrm{A}))$. Hence $\mathrm{f}(\mathrm{A})$ is an IF $\beta C S$ and 
hence is an IF $\pi \mathrm{G} \beta C S$ in $\mathrm{Y}$. Thus $\mathrm{f}$ is an IFA $\pi \mathrm{G} \beta \mathrm{CM}$.

(i) $\Rightarrow$ (iv)Let $A$ be an IFPOS in $X$. Then $A \subseteq \operatorname{int}(\operatorname{cl}(A))$. Since $\operatorname{int}(\operatorname{cl}(\mathrm{A}))$ is an IFROS in $\mathrm{X}$, by hypothesis, $\mathrm{f}(\operatorname{int}(\operatorname{cl}(\mathrm{A})))$ is an IF $\pi$ G $\beta O S$ in $Y$. Since $Y$ is an IF $\pi \beta T 1 / 2$ space, $f(\operatorname{int}(\operatorname{cl}(A)))$ is an IFBOS in $\mathrm{Y}$. Therefore $\mathrm{f}(\mathrm{A}) \subseteq \mathrm{f}(\operatorname{int}(\mathrm{cl}(\mathrm{A}))) \subseteq \beta \operatorname{int}(\mathrm{f}(\operatorname{int}(\mathrm{cl}(\mathrm{A}))))$.

(iv) $\Rightarrow(i)$ Let $A$ be an IFROS in $X$. Then $A$ is an IFPOS in $X$. By hypothesis, $\mathrm{f}(\mathrm{A}) \subseteq \beta \operatorname{int}(\mathrm{f}(\operatorname{int}(\operatorname{cl}(\mathrm{A}))))=\beta \operatorname{int}(\mathrm{f}(\mathrm{A})) \subseteq \mathrm{f}(\mathrm{A})$. This implies $\mathrm{f}(\mathrm{A})$ is an IFßOS in $\mathrm{Y}$ and hence is an $\mathrm{IF} \pi \mathrm{G} \beta \mathrm{OS}$ in $\mathrm{Y}$. Therefore $\mathrm{f}$ is an IFA $\pi \mathrm{G} \beta \mathrm{CM}$.

Theorem 3.19: Let $f: X \rightarrow Y$ be a mapping. Then $f$ is an IFA $\pi \mathrm{G} \beta \mathrm{CM}$ if for each IFP $\mathrm{c}(\alpha, \beta) \in \mathrm{Y}$ and for each IF $\beta O S \mathrm{~B}$ in $\mathrm{X}$ such that $\mathrm{f}^{-1}(\mathrm{c}(\alpha, \beta) \in \mathrm{B}, \quad \beta \mathrm{cl}(\mathrm{f}(\mathrm{B}))$ is an $\operatorname{IF} \beta \mathrm{N}$ of $c(\alpha, \beta) \in \mathrm{Y}$.

Proof: Let $c(\alpha, \beta) \in \mathrm{Y}$ and let $\mathrm{A}$ be an IFROS in $\mathrm{X}$. Then $\mathrm{A}$ is an IF $\beta O S$ in $X$. By hypothesis $\mathrm{f}^{-1}(\mathrm{c}(\alpha, \beta)) \in \mathrm{A}$, that is $c(\alpha, \beta) \in f(A)$ in $Y$ and $\beta \operatorname{cl}((f(A))$ is an IF $\beta N$ of $c(\alpha, \beta)$ in $Y$. Therefore there exists an IF $\beta$ OSB in $\mathrm{Y}$ such that $\mathrm{c}(\alpha, \beta)) \in \mathrm{B}$ $\subseteq \beta \mathrm{cl}(\mathrm{f}(\mathrm{A}))$.We $\quad$ have $\quad \mathrm{c}(\alpha, \beta) \in \mathrm{f}(\mathrm{A}) \subseteq \beta \mathrm{cl}(\mathrm{f}(\mathrm{A}))$. Now $\mathrm{B}=\cup\{\mathrm{c}(\alpha, \beta) / \mathrm{c}(\alpha, \beta) \in \mathrm{B}\}=\mathrm{f}(\mathrm{A})$.

Therefore $\mathrm{f}(\mathrm{A})$ is an IF $\beta O S$ in $\mathrm{Y}$ and hence an IF $\pi \mathrm{G} \beta O \mathrm{OS}$ in $\mathrm{Y}$ Thus $\mathrm{f}$ is an IFA $\pi \mathrm{G} \beta \mathrm{OM}$.

Hence by Theorem $3.15 \mathrm{f}$ is an IFA $\pi \mathrm{G} \beta \mathrm{CM}$.

Theorem 3.20:Let $f: X \rightarrow Y$ be a mapping. If $f$ is an IFA $\pi \mathrm{G} \beta C M$ then $\pi \mathrm{G} \beta \mathrm{cl}(\mathrm{f}(\mathrm{A}) \subseteq \mathrm{f}(\operatorname{cl}(\mathrm{A}))$ for every IF $\beta$ OS $A$ in $\mathrm{X}$.

Proof: Let A be an IF $\beta O S$ in $X$. Then $c l(A)$ is an IFRCS in $X$. By hypothesis $f(\operatorname{cl}(A))$ is an IF $\pi G \beta C S$ in $Y$. Then $\pi \mathrm{G} \beta \operatorname{cl}(\mathrm{f}(\mathrm{cl}(\mathrm{A})) \quad=\quad \mathrm{f}(\operatorname{cl}(\mathrm{A}))$. Now $\pi \mathrm{G} \beta \mathrm{cl}(\mathrm{f}(\mathrm{A})) \subseteq \pi \mathrm{g} \beta \mathrm{cl}(\mathrm{f}(\mathrm{cl}(\mathrm{A}))) \subseteq \mathrm{f}(\operatorname{cl}(\mathrm{A}))$.That is $\pi \mathrm{G} \beta \mathrm{cl}(\mathrm{f}(\mathrm{A}) \subseteq \mathrm{f}(\operatorname{cl}(\mathrm{A}))$.

Corollary 3.21: Let $\mathrm{f}: \mathrm{X} \rightarrow \mathrm{Y}$ be a mapping. If $\mathrm{f}$ is an IFA $\pi \mathrm{G} \beta C M$, then $\pi \mathrm{G} \beta \mathrm{cl}(\mathrm{f}(\mathrm{A}) \subseteq \mathrm{f}(\operatorname{cl}(\mathrm{A}))$ for every IFSOS $A$ in $\mathrm{X}$.

Proof: Since every IFSOS is an IF $\beta O S$, the proof directly follows from the Theorem 3.20

Corollary3.22: Let $\mathrm{f}: \mathrm{X} \rightarrow \mathrm{Y}$ be a mapping. If $\mathrm{f}$ is an IFA $\pi \mathrm{G} \beta \mathrm{CM}$, then $\pi \mathrm{G} \beta \operatorname{cl}(\mathrm{f}(\mathrm{A}) \subseteq \mathrm{fcl}(\mathrm{A}))$ for every IFPOS $A$ in $\mathrm{X}$.

Proof: Since every IFPOS is an IF $\beta O S$, and hence $\pi \mathrm{G} \beta O S$, the proof directly follows from the Theorem 3.20.

Theorem 3.23: Let $f: X \rightarrow Y$ be a mapping. If $f$ is an IFA $\pi \mathrm{G} \beta C M$, then $\pi \mathrm{G} \beta \operatorname{cl}(\mathrm{f}(\mathrm{A})) \subseteq \mathrm{f}(\operatorname{cl}(\beta \operatorname{int}(\mathrm{A})))$ for every IFßOS A in $\mathrm{X}$.

Proof: Let A be an IF $\beta O S$ in $X$. Then cl(A) is an IFRCS in $X$. By hypothesis , $\mathrm{f}(\mathrm{cl}(\mathrm{A}))$ is an IF $\pi \mathrm{G} \beta C S$ in $\mathrm{Y}$.

Then $\quad \pi \mathrm{G} \beta \mathrm{cl}(\mathrm{f}(\mathrm{A})) \quad \subseteq \pi \mathrm{g} \beta \mathrm{cl}(\mathrm{f}(\mathrm{cl}(\mathrm{A})))=\quad \mathrm{f}(\operatorname{cl}(\mathrm{A}))$ $\subseteq \mathrm{f}(\operatorname{cl}(\beta \operatorname{int}(\mathrm{A})))$, since $\operatorname{\beta int}(\mathrm{A})=\mathrm{A}$.

Corollary3.24: Let $f: X \rightarrow Y$ be a mapping. If $f$ is an IFA $\pi \mathrm{G} \beta C M$, then $\pi \mathrm{G} \beta \operatorname{cl}(\mathrm{f}(\mathrm{A})) \subseteq \mathrm{f}(\operatorname{cl}(\beta \operatorname{int}(\mathrm{A})))$ for every IFSOS A in $\mathrm{X}$

Proof: Since every IFSOS is an IF $\beta O S$, the proof directly follows from the Theorem 3.23 .

Corollary3.25: Let $\mathrm{f}: \mathrm{X} \rightarrow \mathrm{Y}$ be a mapping. If $\mathrm{f}$ is an IFA $\pi \mathrm{G} \beta \mathrm{CM}$, then $\pi \mathrm{G} \beta \mathrm{cl}(\mathrm{f}(\operatorname{cl}(\mathrm{A}))) \subseteq \mathrm{f}(\operatorname{cl}(\beta \operatorname{int}(\mathrm{A})))$ for every IFPOS A in $\mathrm{X}$

Proof: Since every IFPOS is an IF $\beta$ OS, the proof directly follows from the Theorem 3.23 .

Theorem 3.26: Let $\mathrm{f}: \mathrm{X} \rightarrow \mathrm{Y}$ be a mapping. If $\mathrm{f}(\beta \operatorname{int}(\mathrm{B})) \subseteq \beta \operatorname{int}(\mathrm{f}(\mathrm{B}))$ for every IFSB in $\mathrm{X}$, then $\mathrm{f}$ is an IFA $\pi \mathrm{G} \beta O M$.

Proof: Let $\mathrm{B} \subseteq \mathrm{X}$ be an IFROS. By hypothesis, $\mathrm{f}(\beta \operatorname{int}(\mathrm{B}))$ $\subseteq \beta \operatorname{int}(\mathrm{f}(\mathrm{B}))$.Since $\mathrm{B}$ is an IFROS, it is an IF $\beta O S$ in $\mathrm{X}$. Therefore $\beta \operatorname{int}(\mathrm{B})=\mathrm{B}$. Hence $\mathrm{f}(\mathrm{B})=\mathrm{f}(\beta \operatorname{int}(\mathrm{B})) \subseteq \beta \operatorname{\beta int}(\mathrm{f}(\mathrm{B}))$ $\subseteq \mathrm{f}(\mathrm{B})$. This implies $\mathrm{f}(\mathrm{B})$ is an IF $\beta O S$ and hence an IF $\pi \mathrm{G} \beta \mathrm{OS}$ in $\mathrm{Y}$. Thus $\mathrm{f}$ is an IFA $\pi \mathrm{G} \beta \mathrm{OM}$.

Theorem 3.27: Let $\mathrm{f}: \mathrm{X} \rightarrow \mathrm{Y}$ be a mapping. If $\beta \operatorname{cl}(\mathrm{f}(\mathrm{B})) \subseteq \mathrm{f}(\beta \mathrm{cl}(\mathrm{B}))$ for every IFSB in $\mathrm{X}$, then $\mathrm{f}$ is an IFA $\pi \mathrm{G} \beta \mathrm{CM}$.

Proof: Let $\mathrm{B} \subseteq \mathrm{X}$ be an IFRCS. By hypothesis, $\beta \mathrm{cl}(\mathrm{f}(\mathrm{B})) \subseteq$ $\mathrm{f}(\beta \mathrm{cl}(\mathrm{B}))$. Since $\mathrm{B}$ is an IFRCS ,it is an IF $\beta C S$ in $X$. Therefore $\beta \operatorname{cl}(B)=B$. Hence $\mathrm{f}(\mathrm{B})=\mathrm{f}(\beta \mathrm{cl}(\mathrm{B})) \supseteq \beta \mathrm{cl}(\mathrm{f}(\mathrm{B}))$ $\supseteq \mathrm{f}(\mathrm{B})$. This implies $\mathrm{f}(\mathrm{B})$ is an IF $\beta C S$ and hence an IF $\pi \mathrm{G} \beta C S$ in $\mathrm{Y}$. Thus $\mathrm{f}$ is an IFA $\pi \mathrm{G} \beta \mathrm{CM}$.

Theorem 3.28: Let $f: X \rightarrow Y$ be a mapping where $Y$ is an IF $\pi \beta T 1 / 2$ space Then the following are equivalent. 
$\mathrm{f}$ is an IFA $\pi \mathrm{G} \beta O M$

for each $\operatorname{IFPc}(\alpha, \beta)$ in $\mathrm{Y}$ and each IFROSB in $\mathrm{X}$ such that $\mathrm{f}^{-}$ ${ }^{1}(\mathrm{c}(\alpha, \beta)) \in \mathrm{B}, \mathrm{cl}(\mathrm{f}(\mathrm{cl}(\mathrm{B})))$ is an $\operatorname{IF} \beta \mathrm{N}$ of $\mathrm{c}(\alpha, \beta)$ in $\mathrm{Y}$.

Proof: (i) $\Rightarrow$ (ii) Let $c(\alpha, \beta) \in \mathrm{Y}$ and let $\mathrm{B}$ be an IFROS in $\mathrm{X}$ such that $\mathrm{f}^{-1}(\mathrm{c}(\alpha, \beta)) \in \mathrm{B}$. That is $\mathrm{c}(\alpha, \beta) \in \mathrm{f}(\mathrm{B})$.

By hypothesis $f(B)$ is an IF $\pi$ G $\beta O S$ in $Y$. Since $Y$ is an $\operatorname{IF} \pi \beta T 1 / 2$ space, $f(B)$ is an IF $\beta O S$ in $Y$.

Now $\mathrm{c}(\alpha, \beta) \in \mathrm{f}(\mathrm{B}) \subseteq \mathrm{f}(\mathrm{cl}(\mathrm{B})) \subseteq \mathrm{cl}(\mathrm{f}(\mathrm{cl}(\mathrm{B})))$. Hence $\mathrm{cl}(\mathrm{f}(\mathrm{cl}(\mathrm{B})))$ is an $\operatorname{IF} \beta N$ of $c(\alpha, \beta)$ in $Y$.

(ii) $\Rightarrow$ (i) Let $B$ be an IFROS in $X$. Then $\mathrm{f}^{-1}(\mathrm{c}(\alpha, \beta)) \in \mathrm{B}$. This implies $\mathrm{c}(\alpha, \beta) \in \mathrm{f}(\mathrm{B})$. By hypothesis, $\operatorname{cl}(\mathrm{f}(\mathrm{cl}(\mathrm{B})))$ is an IFßN of $c(\alpha, \beta)$. Therefore there exists an IF $\beta O$ S A in Y such that $\mathrm{c}(\alpha, \beta) \in \mathrm{A} \subseteq \operatorname{cl}(\mathrm{f}(\mathrm{cl}(\mathrm{B})))$.

Now $A=\cup\{c(\alpha, \beta) / c(\alpha, \beta) \in A\}=f(B)$. Therefore $f(B)$ is an IF $\beta O S$ and hence an IF $\pi$ G $\beta O S$ in $Y$.

Thus $\mathrm{f}$ is an IFA $\pi \mathrm{G} \beta \mathrm{OM}$.

Theorem 3.29: The following are equivalent for a mapping $\mathrm{f}$ $: \mathrm{X} \rightarrow \mathrm{Y}$ where $\mathrm{Y}$ is an IF $\pi \beta T 1 / 2$ space

(i) $\mathrm{f}$ is an $\mathrm{IFA} \pi \mathrm{G} \beta \mathrm{CM}$

(ii) $\beta \mathrm{cl}(\mathrm{f}(\mathrm{A})) \subseteq \mathrm{f}(\alpha \mathrm{cl}(\mathrm{A}))$ for every IF $\beta$ OS A in $\mathrm{X}$

(iii) $\beta \mathrm{cl}(\mathrm{f}(\mathrm{A})) \subseteq \mathrm{f}(\alpha \mathrm{cl}(\mathrm{A}))$ for every $\quad$ IFSOS $\mathrm{A}$ (iv) $\mathrm{f}(\mathrm{A}) \subseteq \beta \operatorname{int}(\mathrm{f}(\operatorname{scl}(\mathrm{A})))$ for every IFPOS $\mathrm{A}$ in $\mathrm{X}$.

Proof:(i) $\Rightarrow$ (ii) Let $A$ be an IFßOS in $X$.Then $c l(A)$ is an IFRCS in X. By hypothesis $\mathrm{f}(\mathrm{A})$ is an IF $\pi \mathrm{G} \beta \mathrm{CS}$ in $\mathrm{Y}$ and hence is an IF $\beta C S$ in $Y$, since $Y$ is an IF $\pi \beta T 1 / 2$ space .This implies $\beta \mathrm{cl}(\mathrm{f}(\mathrm{cl}(\mathrm{A})))=\mathrm{f}(\mathrm{cl}(\mathrm{A}))$.

Now $\beta \operatorname{cl}(f(A)) \subseteq \beta c l(f(\operatorname{cl}(A)))=f(\operatorname{cl}(A))$. Since $\operatorname{cl}(A)$ is(ią) IFRCS, $\operatorname{cl}(\operatorname{int}(\mathrm{cl}(\mathrm{A})))=\operatorname{cl}(\mathrm{A})$.

(iii)

Therefore $\quad \beta \operatorname{cl}(\mathrm{f}(\mathrm{A})) \subseteq \mathrm{f}(\operatorname{cl}(\mathrm{A}))=(\operatorname{cl}(\operatorname{int}(\mathrm{cl}(\mathrm{A})))) \subseteq$ $\mathrm{f}(\mathrm{A} \cup \operatorname{cl}(\operatorname{int}(\operatorname{cl}(\mathrm{A})))) \subseteq \mathrm{f}(\alpha \mathrm{cl}(\mathrm{A}))$.

Hence $\beta \mathrm{cl}(\mathrm{f}(\mathrm{A})) \subseteq \mathrm{f}(\alpha \mathrm{cl}(\mathrm{A}))$.

(ii) $\Rightarrow$ (iii) Let A be an IFSOS in X. Since every IFSOS is an IF $\square$ OS, the proof is obvious.

(iii) $\Rightarrow(\mathrm{i})$ Let $\mathrm{A}$ be an IFRCS in $\mathrm{X}$. Then $\mathrm{A}=\mathrm{cl}(\operatorname{int}(\mathrm{A})$ ). Therefore $\mathrm{A}$ is an IFSOS in X. By hypothesis,

$\beta \mathrm{cl}(\mathrm{f}(\mathrm{A})) \subseteq \mathrm{f}(\alpha \mathrm{cl}(\mathrm{A})) \subseteq \mathrm{f}(\mathrm{cl}(\mathrm{A}))=\mathrm{f}(\mathrm{A}) \subseteq \beta \mathrm{cl}(\mathrm{f}(\mathrm{A}))$. That is $\beta \mathrm{cl}(\mathrm{f}(\mathrm{A}))=\mathrm{f}(\mathrm{A})$.

Hence $\mathrm{f}(\mathrm{A})$ is an IF $\beta C S$ and hence is an $\operatorname{IF} \pi \mathrm{G} \beta \mathrm{CS}$ in $\mathrm{Y}$. Thus $\mathrm{f}$ is an IFA $\pi \mathrm{G} \beta \mathrm{CM}$.

(i) $\Rightarrow$ (iv) Let $A$ be an IFPOS in $X$. Then $A \subseteq \operatorname{int}(\mathrm{cl}(\mathrm{A}))$. Since $\operatorname{int}(\mathrm{cl}(\mathrm{A}))$ is an IFROS in $\mathrm{X}$, by hypothesis $\mathrm{f}(\operatorname{int}(\mathrm{cl}(\mathrm{A})))$ is an IF $\pi \mathrm{G} \beta O S$ in $Y$. Since $Y$ is an $\operatorname{IF} \pi \beta T 1 / 2$ space, $f(\operatorname{int}(\operatorname{cl}(A)))$ is an IFßOS inY.Therefore $\mathrm{f}(\mathrm{A}) \subseteq \mathrm{f}(\operatorname{int}(\mathrm{cl}(\mathrm{A}))) \subseteq$ $\beta \operatorname{int}(f(\operatorname{int}(\mathrm{cl}(\mathrm{A}))))=\beta \operatorname{int}(\mathrm{f}(\mathrm{A} \cup \operatorname{int}(\mathrm{cl}(\mathrm{A}))))$

$=\beta \operatorname{int}(\mathrm{f}(\operatorname{scl}(\mathrm{A})))$. That is $\mathrm{f}(\mathrm{A}) \subseteq \beta \operatorname{int}(\mathrm{f}(\operatorname{scl}(\mathrm{A})))$.

(iv) $\Rightarrow(\mathrm{i})$ Let $\mathrm{A}$ be an IFROS in $\mathrm{X}$. Then $\mathrm{A}$ is an IFPOS in $\mathrm{X}$. By hypothesis, $\mathrm{f}(\mathrm{A}) \subseteq \beta \operatorname{int}(\mathrm{f}(\operatorname{scl}(\mathrm{A})))$. This implies $\mathrm{f}(\mathrm{A}) \subseteq$ $\beta \operatorname{int}(\mathrm{f}(\mathrm{A} \cup \operatorname{int}(\mathrm{cl}(\mathrm{A})))) \subseteq \beta \operatorname{int}(\mathrm{f}(\mathrm{A} \cup \mathrm{A}))=\beta \operatorname{int}(\mathrm{f}(\mathrm{A})) \subseteq$ $\mathrm{f}(\mathrm{A})$. Therefore $\mathrm{f}(\mathrm{A})$ is an IF $\beta O S$ in $\mathrm{Y}$ and hence an IF $\pi \mathrm{G} \beta O S$ in $\mathrm{Y}$. Thus $\mathrm{f}$ is an IFA $\pi \mathrm{G} \beta \mathrm{CM}$ by Theorem 3.13

Theorem 3.30: Let $f: X \rightarrow Y$ be a mapping where $Y$ is an IF $\pi \beta T 1 / 2$ space. If $\mathrm{f}$ is an IFA $\pi \mathrm{G} \beta \mathrm{CM}$, then $\operatorname{int}(\operatorname{cl}(\operatorname{int}(f(B)))) \subseteq f(\beta c l(B))$ for every IFRCS B in X.

Proof: Let $\mathrm{B} \subseteq \mathrm{X}$ be an IFRCS. By hypothesis, $\mathrm{f}(\mathrm{B})$ is an $\mathrm{IF} \pi \mathrm{G} \beta C \mathrm{CS}$ in $\mathrm{Y}$. Since $\mathrm{Y}$ is an $\operatorname{IF} \pi \beta \mathrm{T}_{1 / 2}$ space, $\mathrm{f}(\mathrm{B})$ is an IF $\beta C S$ in $Y$. Therefore $\beta \mathrm{cl}(\mathrm{f}(\mathrm{B}))=\mathrm{f}(\mathrm{B})$. Now int $(\mathrm{cl}(\operatorname{int}(\mathrm{f}(\mathrm{B}))))$ $\subseteq \mathrm{f}(\mathrm{B}) \cup \operatorname{int}(\mathrm{cl}(\operatorname{int}(\mathrm{f}(\mathrm{B}))))=\beta \mathrm{cl}(\mathrm{f}(\mathrm{B}))=\mathrm{f}(\mathrm{B})=\mathrm{f}(\beta \mathrm{cl}(\mathrm{B}))$.

Hence $\operatorname{int}(\operatorname{cl}(\operatorname{int}(\mathrm{f}(\mathrm{B})))) \subseteq \mathrm{f}(\beta \mathrm{cl}(\mathrm{B}))$.

Theorem 3.31 Let $\mathrm{f}$ : $\mathrm{X} \pi \mathrm{Y}$ be a mapping where $\mathrm{Y}$ is an IF $\pi \beta T_{1 / 2}$ space. If $f$ is an IFA $\pi \mathrm{G} \beta C M$, then $\mathrm{f}(\beta \operatorname{int}(\mathrm{B})) \subseteq \mathrm{cl}(\operatorname{int}(\mathrm{cl}(\mathrm{f}(\mathrm{B}))))$ for every IFROS B in X.

Proof: This theorem can be easily proved by taking complement in Theorem 3.30

Theorem3.32: Let $\mathrm{f}:(\mathrm{X}, \tau) \rightarrow(\mathrm{Y}, \sigma)$ be a mapping from an IFTS $\mathrm{X}$ into an IFTS $\mathrm{Y}$. Then the following conditions are equivalent if $\mathrm{Y}$ is an $\mathrm{IF} \pi \beta \mathrm{T} 1 / 2$ space.

$\mathrm{f}$ is an IFA $\pi \mathrm{G} \beta \mathrm{CM}$

$\mathrm{f}$ is an IFA $\pi \mathrm{G} \beta \mathrm{OM}$

$\mathrm{f}(\operatorname{int}(\mathrm{A})) \subseteq \operatorname{int}(\mathrm{cl}(\operatorname{int}(\mathrm{f}(\mathrm{A}))))$ for every IFROS A in X.

Proof : (i) $\Rightarrow$ (ii) It is obviously true.

(ii) $\Rightarrow$ (iii) Let $A$ be any IFROS in $X$. This implies $A$ is an IFOS in X. Then $\operatorname{int}(A)$ is an IFOS in X. Then $f(\operatorname{int}(A))$ is an IF $\pi \mathrm{G} \beta \mathrm{OS}$ in $\mathrm{Y}$. Since $\mathrm{Y}$ is an IF $\pi \beta T 1 / 2$ space, $\mathrm{f}(\operatorname{int}(\mathrm{A}))$ is an IFOS in Y.

Therefore $\mathrm{f}(\operatorname{int}(\mathrm{A}))=\operatorname{int}(\mathrm{f}(\operatorname{int}(\mathrm{A})) \subseteq \operatorname{int}(\operatorname{cl}(\operatorname{int}(\mathrm{f}(\mathrm{A}))))$. (iii) $\Rightarrow$ (i) Let $A$ be an IFRCS in $X$. Then its complement $A^{c}$ is an IFROS in X. By hypothesis

$\mathrm{f}\left(\operatorname{int}\left(\mathrm{A}^{\mathrm{c}}\right)\right) \subseteq \operatorname{int}\left(\mathrm{cl}\left(\operatorname{int}\left(\mathrm{f}\left(\mathrm{A}^{\mathrm{c}}\right)\right)\right)\right)$.This implies $\left.\mathrm{f}^{\mathrm{c}} \mathrm{A}^{\mathrm{c}}\right) \subseteq$ $\operatorname{int}\left(\operatorname{cl}\left(\operatorname{int}\left(f\left(A^{c}\right)\right)\right)\right)$. Hence $f\left(A^{c}\right)$ is an IF $\alpha O S$ in $Y$.

Since every IF $\alpha O S$ is an IF $\pi$ G $\beta O S, f\left(A^{c}\right)$ is an IF $\pi G \beta O S$ in $\mathrm{Y}$. Therefore $\mathrm{f}(\mathrm{A})$ is an $\operatorname{IF} \pi \mathrm{G} \beta \mathrm{CS}$ in $\mathrm{Y}$. Hence $\mathrm{f}$ is an IFA $\pi \mathrm{G} \beta \mathrm{CM}$. 
Theorem 3.33 Let $\mathrm{f}:(\mathrm{X}, \tau) \rightarrow(\mathrm{Y}, \sigma)$ be an IFA closed mapping and $\mathrm{g}:(\mathrm{Y}, \sigma) \rightarrow(\mathrm{Z}, \delta)$ is IFA $\pi \mathrm{G} \beta$ closed mapping, then $\mathrm{g}_{0} f:(\mathrm{X}, \tau) \rightarrow(\mathrm{Z}, \delta)$ is an IFA closed mapping. if $Z$ is an IF $\pi \beta T 1 / 2$ space.

Proof: Let A be an IFRCS in X. Then $\mathrm{f}(\mathrm{A})$ is an IFCS in Y. Since $g$ is an IF $\pi G \beta$ closed mapping, $g(f(A))$ is an IF $\pi \mathrm{G} \beta C S$ in $\mathrm{Z}$. Therefore $\mathrm{g}(\mathrm{f}(\mathrm{A}))$ is an IFCS in $\mathrm{Z}$, by hypothesis. Hence $\mathrm{g}_{\square} \mathrm{f}$ is an IFA closed mapping.

Theorem 3.34 Let $\mathrm{f}:(\mathrm{X}, \tau) \rightarrow(\mathrm{Y}, \sigma)$ be an IFA closed mapping and $\mathrm{g}:(\mathrm{Y}, \sigma) \rightarrow(\mathrm{Z}, \eta)$ be an $\mathrm{IF} \pi \mathrm{G} \beta$ closed mapping. Then gof $:(X, \tau) \rightarrow(Z, \eta)$ is an IFA $\pi \mathrm{G} \beta$ closed mapping.

Proof: Let A be an IFRCS in X. Then $\mathrm{f}(\mathrm{A})$ is an IFCS in Y, by hypothesis. Since $\mathrm{g}$ is an $\mathrm{IF} \pi \mathrm{G} \beta$ closed mapping, $\mathrm{g}(\mathrm{f}(\mathrm{A})$ ) is an IF $\pi \mathrm{G} \beta C$ S in $Z$. Hence gof is an IFA $\pi \mathrm{G} \beta$ closed mapping.

Theorem 3.35 If $f:(X, \tau) \rightarrow(Y, \sigma)$ is an IFA $\pi G \beta$ closed mapping and $\mathrm{Y}$ is an IF $\pi \beta T 1 / 2$ space, then $\mathrm{f}(\mathrm{A})$ is an IFGCS in $\mathrm{Y}$ for every IFRCS $\mathrm{A}$ in $\mathrm{X}$.

Proof: Let $\mathrm{f}:(\mathrm{X}, \tau) \rightarrow(\mathrm{Y}, \sigma)$ be a mapping and let $\mathrm{A}$ be an IFRCS in $X$. Then by hypothesis $\mathrm{f}(\mathrm{A})$ is an IF $\pi \mathrm{G} \beta C \mathrm{C}$ in $\mathrm{Y}$. Since $\mathrm{Y}$ is an IF $\pi \beta T 1 / 2$ space, $\mathrm{f}(\mathrm{A})$ is an IFGCS in $\mathrm{Y}$.

Theorem 3.36 Let $\mathrm{f}: \mathrm{X} \rightarrow \mathrm{Y}$ be a bijective mapping. Then the following are equivalent.
(i) $\mathrm{f}$ is an IFA $\pi \mathrm{G} \beta O \mathrm{OM}$.
(ii) $\mathrm{f}$ is an IFA $\pi \mathrm{G} \beta \mathrm{CM}$.
(iii) $\mathrm{f}^{-1}$ is an IFA $\pi \mathrm{G} \beta$ continuous mapping.

Proof : (i) $\Rightarrow$ (ii) is obvious from the Theorem 3.15 .

(ii) $\Rightarrow$ (iii) Let $\mathrm{A} \subseteq \mathrm{X}$ be an IFRCS. Then by hypothesis, $\mathrm{f}(\mathrm{A})$ is an IF $\pi \mathrm{G} \beta C S$ in $Y$. That is $\left(\mathrm{f}^{-1}\right)^{-1}(\mathrm{~A})$ is an IF $\pi \mathrm{G} \beta C \mathrm{CS}$ in $Y$. This implies $\mathrm{f}^{-1}$ is an IFA $\pi \mathrm{G} \beta$ continuous mapping. (iii) $\Rightarrow$ (ii) Let $\mathrm{A} \subseteq \mathrm{X}$ be an IFRCS. Then by hypothesis ( $\mathrm{f}$ $\left.{ }^{1}\right)^{-1}(A)$ is an IF $\pi G \beta C S$ in $Y$. That is $f(A)$ is an IF $\pi G \beta C S$ in $\mathrm{Y}$. Hence $\mathrm{f}$ is an IFA $\pi \mathrm{G} \beta \mathrm{CM}$.

Theorem 3.37 Let $\mathrm{f}: \mathrm{X} \rightarrow \mathrm{Y}$ be an IFA $\pi \mathrm{G} \beta \mathrm{OM}$, where $\mathrm{Y}$ is an IF $\pi \beta T 1 / 2$ space. Then for each IFP $c(\alpha, \beta)$ in $Y$ and each IFROS B in X such that $\mathrm{f}^{-1}(\mathrm{c}(\alpha, \beta)) \in \mathrm{B}, \operatorname{cl}(\mathrm{f}(\mathrm{cl}(\mathrm{B})))$ is an $\operatorname{IF} \beta \mathrm{N}$ of $\mathrm{c}(\alpha, \beta)$ in $\mathrm{Y}$.
Proof: Let $c(\alpha, \beta) \in Y$ and let $B$ be an IFROS in $X$ such that $\mathrm{f}^{-1}(\mathrm{c}(\alpha, \beta)) \in \mathrm{B}$. That is $\mathrm{c}(\alpha, \beta) \in \mathrm{f}(\mathrm{B})$. By hypothesis, $\mathrm{f}(\mathrm{B})$ is an IF $\pi \mathrm{G} \beta \mathrm{OS}$ in $\mathrm{Y}$. Since $\mathrm{Y}$ is an IF $\pi \beta T 1 / 2$ space, $\mathrm{f}(\mathrm{B})$ is an IFßOS in $\mathrm{Y}$.

Now $\mathrm{c}(\alpha, \beta) \in \mathrm{f}(\mathrm{B}) \subseteq \mathrm{f}(\mathrm{cl}(\mathrm{B})) \subseteq \mathrm{cl}(\mathrm{f}(\mathrm{cl}(\mathrm{B})))$. Hence $\mathrm{cl}(\mathrm{f}(\mathrm{cl}(\mathrm{B})))$ is an IF $\beta \mathrm{N}$ of $\mathrm{c}(\alpha, \beta)$ in $\mathrm{Y}$.

Remark 3.38 If an IFS A in an IFTS $(\mathrm{X}, \tau)$ is an IF $\pi \mathrm{G} \beta \mathrm{CS}$ in $\mathrm{X}$, then $\pi \mathrm{g} \beta \mathrm{cl}(\mathrm{A})=\mathrm{A}$. But the converse may not be true in general, since the intersection does not exist in IF $\pi$ G $\beta C S s$.

Remark 3.39If an IFS A in an IFTS $(X, \tau)$ is an IF $\pi \mathrm{G} \beta O S$ in $\mathrm{X}$, then $\pi \mathrm{g} \beta \operatorname{int}(\mathrm{A})=\mathrm{A}$. But the converse may not be true in general, since the union does not exist in IF $\pi$ G $\beta O S$ s.

Theorem 3.40 Let $\mathrm{f}: \mathrm{X} \rightarrow \mathrm{Y}$ be a mapping. If $\mathrm{f}$ is an IFA $\pi \mathrm{G} \beta C \mathrm{CM}$, then $\pi \mathrm{g} \beta \mathrm{cl}(\mathrm{f}(\mathrm{A})) \subseteq \mathrm{f}(\mathrm{cl}(\mathrm{A}))$ for every IF $\beta O S$ A in $\mathrm{X}$.

Proof: Let A be an IF $\beta O S$ in X. Then cl(A) is an IFRCS in $X$. By hypothesis $\mathrm{f}(\mathrm{cl}(\mathrm{A}))$ is an $\mathrm{IF} \pi \mathrm{G} \beta \mathrm{CS}$ in $\mathrm{Y}$. Then $\pi \mathrm{g} \beta \mathrm{cl}(\mathrm{f}(\mathrm{cl}(\mathrm{A}))=\mathrm{f}(\operatorname{cl}(\mathrm{A}))$. Now $\pi \mathrm{g} \beta \operatorname{cl}(\mathrm{f}(\mathrm{A})) \subseteq$ $\mathrm{g} \beta \mathrm{cl}(\mathrm{f}(\mathrm{cl}(\mathrm{A})))=\mathrm{f}(\mathrm{cl}(\mathrm{A}))$.

That is $\pi \mathrm{g} \beta \mathrm{cl}(\mathrm{f}(\mathrm{A})) \subseteq \mathrm{f}(\mathrm{cl}(\mathrm{A}))$.

Corollary 3.41 Let $\mathrm{f}: \mathrm{X} \rightarrow \mathrm{Y}$ be a mapping. If $\mathrm{f}$ is an IFA $\pi \mathrm{G} \beta \mathrm{CM}$, then $\pi \mathrm{g} \beta \mathrm{cl}(\mathrm{f}(\mathrm{A}) \subseteq \mathrm{f}(\operatorname{cl}(\mathrm{A}))$ for every $\mathrm{IF} \pi \mathrm{G} \beta \mathrm{OS}$ $\mathrm{A}$ in $\mathrm{X}$.

Proof: Since every IFSOS is an IFG $\beta O S$, the proof is obvious from the Theorem 3.40 .

Corollary 3.42 Let $\mathrm{f}: \mathrm{X} \rightarrow \mathrm{Y}$ be a mapping. If $\mathrm{f}$ is an IFA $\pi \mathrm{G} \beta \mathrm{CM}$, then $\pi \mathrm{g} \beta \mathrm{cl}(\mathrm{f}(\mathrm{A}) \subseteq \mathrm{f}(\mathrm{cl}(\mathrm{A}))$ for every IFGOS A in $\mathrm{X}$.

Proof: Since every IFGOS is an IF $\pi \mathrm{G} \beta O S$, the proof is obvious from the Theorem 3.38.

Theorem 3.43 Let $\mathrm{f}: \mathrm{X} \rightarrow \mathrm{Y}$ be a mapping. If $\mathrm{f}$ is an IFA $\pi \mathrm{G} \beta \mathrm{CM}$, then $\pi \mathrm{g} \beta \operatorname{cl}(\mathrm{f}(\mathrm{A})) \subseteq \mathrm{f}(\mathrm{cl}(\beta \operatorname{int}(\mathrm{A})))$ for every IF $\beta O S$ A in $\mathrm{X}$.

Proof: Let A be an IFßOS in X. Then cl(A) is an IFRCS in $X$. By hypothesis, $f(\operatorname{cl}(A))$ is an $\operatorname{IF} \pi \mathrm{G} \beta C S$ in $Y$.

Then $\pi \mathrm{g} \beta \operatorname{cl}(\mathrm{f}(\mathrm{A})) \subseteq \pi \mathrm{g} \beta \operatorname{cl}(\mathrm{f}(\mathrm{cl}(\mathrm{A})))=\mathrm{f}(\mathrm{cl}(\mathrm{A})) \subseteq$ $\mathrm{f}(\operatorname{cl}(\beta \operatorname{int}(\mathrm{A})))$, since $\beta \operatorname{int}(\mathrm{A})=\mathrm{A}$. 


\section{4: INTUITIONISTIC FUZZY CONTRA $\pi \mathrm{G} \beta$ OPEN MAPPINGS}

In this section we have introduced intuitionistic fuzzy contra $\pi \mathrm{G} \beta$ open mappings. We have investigated some of its properties.

Definition 4.1: A mapping $f:(X, \tau) \rightarrow(Y, \sigma)$ is said to be an intuitionistic fuzzy contra $\pi$ generalized beta open mapping (IFC $\pi \mathrm{G} \beta O M$ for short) if $\mathrm{f}(\mathrm{A})$ is an IF $\pi \mathrm{G} \beta C \mathrm{C}$ in $\mathrm{Y}$ for every IFOS A in $\mathrm{X}$.

Example 4.2: Let $X=\{a, b\}, Y=\{u, v\}$ and $G 1=\langle x,(0.3$, $0.1),(0.6,0.7)\rangle, \mathrm{G} 2=\langle\mathrm{y},(0.5,0.4),(0.5,0.6)\rangle$. Then $\tau=$ $\{0 \sim, \mathrm{G} 1,1 \sim\}$ and $\sigma=\{0 \sim, \mathrm{G} 2,1 \sim\}$ are IFTs on $\mathrm{X}$ and $\mathrm{Y}$ respectively. Define a mapping $\mathrm{f}:(\mathrm{X}, \tau) \rightarrow(\mathrm{Y}, \sigma)$ by $\mathrm{f}(\mathrm{a})=\mathrm{u}$ and $f(b)=v$. Then $f$ is an IFC $\pi$ G $\beta O M$.

Definition 4.3: A mapping $\mathrm{f}:(\mathrm{X}, \tau) \rightarrow(\mathrm{Y}, \sigma)$ is called an intuitionistic fuzzy contra $\pi$ generalized beta closed mapping (IFC $\pi \mathrm{G} \beta$ closed in short) if for every IFCS A of $(\mathrm{X}, \tau), \mathrm{f}(\mathrm{A})$ is an IF $\pi \mathrm{G} \beta O \mathrm{OS}$ in $(\mathrm{Y}, \sigma)$.

Theorem 4.4: For a bijective mapping $\mathrm{f}:(\mathrm{X}, \tau) \rightarrow(\mathrm{Y}, \sigma)$, where $\mathrm{Y}$ is an $\mathrm{IF} \pi \beta T 1 / 2$ space, the following statements are equivalent:

(i) $\mathrm{f}$ is an IFC $\pi \mathrm{g} \beta \mathrm{OM}$.

(ii) for every IFCS A in $X, f(A)$ is an IF $\pi G \beta O S$ in $Y$

(iii) for every IFOS $B$ in $X, f(B)$ is an IF $\pi G \beta C S$ in $Y$.

(iv) for any IFCS $A$ in $X$ and for any IFP $p(\alpha, \beta) \in Y$, if $\mathrm{f}^{-1}$ $(\mathrm{p}(\alpha, \beta)) \mathrm{q} A$, then $\mathrm{p}(\alpha, \beta) \mathrm{q} \beta \operatorname{int}(\mathrm{f}(\mathrm{A}))$

(v) For any IFCS $A$ in $X$ and for any $p(\alpha, \beta) \in Y$, if $f^{-1}(p(\alpha$, $\beta$ ) $\mathrm{qA}$, then there exists an IF $\pi \mathrm{G} \beta O \mathrm{OS}$ B such that $\mathrm{p}(\alpha, \beta) \mathrm{qB}$ and $\mathrm{f}^{-1}(\mathrm{~B}) \subseteq \mathrm{A}$.

Proof: (i) $\Rightarrow$ (ii) Let $A$ be an IFCS in $X$. Then $A^{c}$ is an IFOS in X. By hypothesis, $f\left(A^{c}\right)$ is an IF $\pi G \beta C S$ in $Y$. That is $f(A)^{c}$ is an IF $\pi \mathrm{G} \beta \mathrm{CS}$ in $\mathrm{Y}$. Hence $\mathrm{f}(\mathrm{A})$ is an IF $\pi \mathrm{g} \beta \mathrm{OS}$ in $\mathrm{Y}$.

(ii) $\Rightarrow$ (i) Let $A$ be an IFOS in X. Then $A^{c}$ is an IFCS in $X$. By hypothesis, $f\left(A^{c}\right)=(f(A))^{c}$ is an IF $\pi G \beta O S$ in Y. Hence $\mathrm{f}(\mathrm{A})$ is an IF $\pi \mathrm{G} \beta \mathrm{CS}$ in $\mathrm{Y}$. Thus $\mathrm{f}$ is an IFC $\pi \mathrm{G} \beta O M$.

(ii) $\Rightarrow$ (iii) is obvious.

(ii) $\Rightarrow$ (iv) Let $\mathrm{A} \subseteq \mathrm{X}$ be an IFCS and let $\mathrm{p}(\alpha, \beta) \in \mathrm{Y}$. Assume that $\mathrm{f}^{-1}(\mathrm{p}(\alpha, \beta)) \mathrm{q} A$. Then $\mathrm{p}(\alpha, \beta) \mathrm{q} \mathrm{f}(\mathrm{A})$. By hypothesis, $\mathrm{f}(\mathrm{A})$ is an IF $\pi \mathrm{G} \beta \mathrm{OS}$ in $\mathrm{Y}$. Since $\mathrm{Y}$ is an IF $\beta T 1 / 2$ space, $\mathrm{f}(\mathrm{A})$ is an IF $\beta O S$ in $Y$. This implies $\beta \operatorname{int}(\mathrm{f}(\mathrm{A}))=\mathrm{f}(\mathrm{A})$. Hence $\mathrm{p}(\alpha$,
B) $q \beta \operatorname{int}(f(A))$.

(iv) $\Rightarrow$ (ii) Let $\mathrm{A} \subseteq \mathrm{X}$ be an IFCS and let $\mathrm{p}(\alpha, \beta) \in \mathrm{Y}$. Assume that $\mathrm{f}^{-1}(\mathrm{p}(\alpha, \beta)) \mathrm{q} A$. Then $\mathrm{p}(\alpha, \beta) \mathrm{q} f(A)$. By hypothesis $\mathrm{p}(\alpha, \beta) \mathrm{q} \beta \operatorname{int}(\mathrm{f}(\mathrm{A}))$. That is $\mathrm{f}(\mathrm{A}) \subseteq \beta \operatorname{int}(\mathrm{f}(\mathrm{A}))$ $\subseteq \mathrm{f}(\mathrm{A})$. Therefore $\mathrm{f}(\mathrm{A})=\operatorname{\beta int}(\mathrm{f}(\mathrm{A}))$ is an IFßOS in $\mathrm{Y}$ and hence an IF $\pi \mathrm{G} \beta \mathrm{OS}$ in $\mathrm{Y}$.

(iv) $\Rightarrow$ (v) Let $\mathrm{A} \subseteq \mathrm{X}$ be an IFCS and let $\mathrm{p}(\alpha, \beta) \in \mathrm{Y}$. Assume that $\mathrm{f}^{-1}(\mathrm{p}(\alpha, \beta)) \mathrm{q} A$. Then $\mathrm{p}(\alpha, \beta) \mathrm{q} f(\mathrm{~A})$. This implies $\mathrm{p}(\alpha, \beta) \mathrm{q} \beta \operatorname{int}(\mathrm{f}(\mathrm{A}))$. Thus $\mathrm{f}(\mathrm{A})$ is an IF $\beta O S$ in $\mathrm{Y}$ and hence an IF $\pi \mathrm{G} \beta O \mathrm{OS}$ in $\mathrm{Y}$. Let $\mathrm{f}(\mathrm{A})=\mathrm{B}$.

Therefore $\mathrm{p}(\alpha, \beta) \mathrm{q} B$ and $\mathrm{f}^{-1}(\mathrm{~B})=\mathrm{f}^{-1}(\mathrm{f}(\mathrm{A})) \subseteq \mathrm{A}$.

(v) $\Rightarrow$ (iv) Let $A \subseteq X$ be an IFCS and let $p(\alpha, \beta) \in Y$. Assume that $\mathrm{f}^{-1}(\mathrm{p}(\alpha, \beta)) \mathrm{q}$ A. Then $\mathrm{p}(\alpha, \beta) \mathrm{q} \mathrm{f}(\mathrm{A})$. By hypothesis there exists an IF $\pi$ G $\beta O S$ B in $Y$ such that $p(\alpha, \beta) q$ B and $f$ ${ }^{1}(\mathrm{~B}) \subseteq \mathrm{A}$. Let $\mathrm{B}=\mathrm{f}(\mathrm{A})$.

Then $p(\alpha, \beta) q f(A)$. Since $Y$ is an IF $\beta T 1 / 2$ space, $f(A)$ is an IF $\beta O S$ in $Y$. Therefore $p(\alpha, \beta) q \beta \operatorname{int}(f(A))$.

Theorem 4.5: Let $\mathrm{f}:(\mathrm{X}, \tau) \rightarrow(\mathrm{Y}, \sigma)$ be a bijective mapping. Suppose that one of the following properties hold:

(i) $f(\operatorname{cl}(B)) \subseteq \operatorname{int}(\beta c l(f(B)))$ for each IFS B in $X$

(ii) $\mathrm{cl}(\beta \operatorname{int}(\mathrm{f}(\mathrm{B}))) \subseteq \mathrm{f}(\operatorname{int}(\mathrm{B}))$ for each IFS B in $\mathrm{X}$

(iii) $\mathrm{f}^{-1}(\operatorname{cl}(\beta \operatorname{int}(A))) \subseteq \operatorname{int}\left(\mathrm{f}^{-1}(\mathrm{~A})\right)$ for each IFS A in $\mathrm{Y}$

(iv) $\mathrm{f}^{-1}(\mathrm{cl}(\mathrm{A})) \subseteq \operatorname{int}\left(\mathrm{f}^{-1}(\mathrm{~A})\right)$ for each IFßOS A in $\mathrm{Y}$

Then $\mathrm{f}$ is an IFC $\pi \mathrm{G} \beta O M$.

Proof: (i) $\Rightarrow$ (ii) is obvious by taking the complement in (i). (ii) $\Rightarrow$ (iii) Let $\mathrm{A} \subseteq \mathrm{Y}$. Put $\mathrm{B}=\mathrm{f}^{-1}(\mathrm{~A})$ in $\mathrm{X}$. This implies $\mathrm{A}=$ $\mathrm{f}(\mathrm{B})$ in $\mathrm{Y}$.

Now $\operatorname{cl}(\beta \operatorname{int}(\mathrm{A}))=\operatorname{cl}(\operatorname{\beta int}(\mathrm{f}(\mathrm{B}))) \subseteq \mathrm{f}(\operatorname{int}(\mathrm{B}))$ by (ii).

Therefore $\mathrm{f}^{-1}(\operatorname{cl}(\beta \operatorname{int}(\mathrm{A}))) \subseteq \mathrm{f}^{-1}(\mathrm{f}(\operatorname{int}(\mathrm{B})))=\operatorname{int}(\mathrm{B})=\operatorname{int}(\mathrm{f}$ (A)).

(iii) $\Rightarrow$ (iv) Let $\mathrm{A} \subseteq \mathrm{Y}$ be an $\operatorname{IF\beta OS}$. Then $\beta \operatorname{int}(\mathrm{A})=\mathrm{A}$. By hypothesis, $\mathrm{f}^{-1}(\operatorname{cl}(\operatorname{\beta int}(\mathrm{A}))) \subseteq \operatorname{int}\left(\mathrm{f}^{-1}(\mathrm{~A})\right)$.

Therefore $\mathrm{f}^{-1}(\mathrm{cl}(\mathrm{A})) \subseteq \operatorname{int}\left(\mathrm{f}^{-1}(\mathrm{~A})\right)$.

Suppose (iv) holds: Let A be an IFOS in X. Then $\mathrm{f}(\mathrm{A})$ is an IFS in $Y$ and $\beta \operatorname{int}(f(A))$ is an IFßOS in $Y$. Hence by hypothesis, we have $\mathrm{f}^{-1}(\operatorname{cl}(\operatorname{\beta int}(\mathrm{f}(\mathrm{A})))) \subseteq \operatorname{int}\left(\mathrm{f}^{-1}(\operatorname{\beta int}(\mathrm{f}(\mathrm{A})))\right)$ $\subseteq \operatorname{int}\left(\mathrm{f}^{-1}(\mathrm{f}(\mathrm{A}))\right)=\operatorname{int}(\mathrm{A}) \subseteq \mathrm{A}$.

Therefore $\operatorname{cl}(\beta \operatorname{int}(\mathrm{f}(\mathrm{A})))=\mathrm{f}\left(\mathrm{f}^{-1}(\mathrm{cl}(\operatorname{\beta int}(\mathrm{f}(\mathrm{A}))))\right) \subseteq \mathrm{f}(\mathrm{A})$. Now $\operatorname{cl}(\operatorname{int}(\mathrm{f}(\mathrm{A}))) \subseteq \operatorname{cl}(\operatorname{\beta int}(\mathrm{f}(\mathrm{A}))) \subseteq \mathrm{f}(\mathrm{A})$.

This implies $\mathrm{f}(\mathrm{A})$ is an IFPCS in $\mathrm{Y}$ and hence an IF $\pi \mathrm{G} \beta \mathrm{CS}$ in $\mathrm{Y}$. Thus $\mathrm{f}$ is an IFC $\pi \mathrm{G} \beta \mathrm{OM}$.

Theorem 4.6: Let $\mathrm{f}:(\mathrm{X}, \tau) \rightarrow(\mathrm{Y}, \sigma)$ be a bijective mapping. Suppose that one of the following properties hold: 
(i) $\mathrm{f}^{-1}(\beta \mathrm{cl}(\mathrm{A})) \subseteq \operatorname{int}\left(\mathrm{f}^{-1}(\mathrm{~A})\right)$ for each IFS A in $\mathrm{Y}$

(ii) $\beta \mathrm{cl}(\mathrm{f}(\mathrm{B})) \subseteq \mathrm{f}(\operatorname{int}(\mathrm{B}))$ for each IFS B in $\mathrm{X}$

(iii) $\mathrm{f}(\mathrm{cl}(\mathrm{B})) \subseteq \beta \operatorname{\beta int}(\mathrm{f}(\mathrm{B}))$ for each IFS B in $\mathrm{X}$ Then $\mathrm{f}$ is an IFC $\pi \mathrm{G} \beta \mathrm{OM}$.

Proof: (i) $\Rightarrow$ (ii) Let $\mathrm{B} \subseteq \mathrm{X}$. Then $\mathrm{f}(\mathrm{B})$ is an IFS in $\mathrm{Y}$. By hypothesis, $\mathrm{f}^{-1}(\beta \mathrm{cl}(\mathrm{f}(\mathrm{B}))) \subseteq \operatorname{int}\left(\mathrm{f}^{-1}(\mathrm{f}(\mathrm{B}))\right)=\operatorname{int}(\mathrm{B})$.

Now $\beta \operatorname{cl}(\mathrm{f}(\mathrm{B}))=\mathrm{f}\left(\mathrm{f}^{-1}(\beta \mathrm{cl}(\mathrm{f}(\mathrm{B})))\right) \subseteq \mathrm{f}(\operatorname{int}(\mathrm{B}))$.

(ii) $\Rightarrow$ (iii) is obvious by taking complement in (ii).

Suppose (iii) holds. Let B be an IFCS in X. Then $\operatorname{cl}(\mathrm{B})=\mathrm{B}$ and $f(B)$ is an IFS in $Y$.

Now $\mathrm{f}(\mathrm{B})=\mathrm{f}(\mathrm{cl}(\mathrm{B})) \subseteq \beta \operatorname{int}(\mathrm{f}(\mathrm{B})) \subseteq \mathrm{f}(\mathrm{B})$, by hypothesis. This implies $\mathrm{f}(\mathrm{B})$ is an IF $\beta O S$ in $\mathrm{Y}$ and

Hence an IF $\pi \mathrm{G} \beta O S$ in $Y$. Thus $f$ is an IFC $\pi G \beta O M$ by Theorem 4.4.

Theorem 4.7: Let $\mathrm{f}:(\mathrm{X}, \tau) \rightarrow(\mathrm{Y}, \sigma)$ be a bijective mapping. Then $\mathrm{f}$ is an IFC $\pi \mathrm{G} \beta O M$ if

$\operatorname{cl}\left(f^{-1}(A)\right) \subseteq \mathrm{f}^{-1}(\beta \operatorname{int}(A))$ for every IFS A in $Y$.

Proof: Let $A$ be an IFCS in $\mathrm{X}$. Then $\mathrm{cl}(\mathrm{A})=\mathrm{A}$ and $\mathrm{f}(\mathrm{A})$ is an IFS in Y. By hypothesis

$\operatorname{cl}\left(\mathrm{f}^{-1}(\mathrm{f}(\mathrm{A}))\right) \subseteq \mathrm{f}^{-1}(\beta \operatorname{int}(\mathrm{f}(\mathrm{A})))$. Therefore $\mathrm{A}=\operatorname{cl}(\mathrm{A})=\operatorname{cl}(\mathrm{f}$ $\left.{ }^{1}(f(A))\right) \subseteq f^{-1}(\beta \operatorname{int}(f(A)))$.

Now $\mathrm{f}(\mathrm{A}) \subseteq \mathrm{f}\left(\mathrm{f}^{-1}(\operatorname{\beta int}(\mathrm{f}(\mathrm{A})))\right)=\operatorname{\beta int}(\mathrm{f}(\mathrm{A})) \subseteq \mathrm{f}(\mathrm{A})$. Hence $\mathrm{f}(\mathrm{A})$ is an IF $\beta O S$ in $\mathrm{Y}$ and hence an IF $\pi \mathrm{G} \beta \mathrm{OS}$ in $\mathrm{Y}$. Thus $\mathrm{f}$ is an IFC $\pi \mathrm{G} \beta \mathrm{OM}$ by Theorem 4.4.

Theorem 4.8: If $\mathrm{f}:(\mathrm{X}, \tau) \rightarrow(\mathrm{Y}, \sigma)$ is an IFC $\pi \mathrm{G} \beta \mathrm{OM}$, where $\mathrm{Y}$ is an IF $\beta T 1 / 2$ space, then the following conditions are hold:

(i) $\beta \operatorname{cl}(f(B)) \subseteq f(\operatorname{int}(\beta \operatorname{cl}(B)))$ for every IFOS B in $X$

(ii) $\mathrm{f}(\operatorname{cl}(\beta \operatorname{int}(\mathrm{B}))) \subseteq \beta \operatorname{int}(\mathrm{f}(\mathrm{B}))$ for every IFCS B in $\mathrm{X}$

Proof: (i) Let $\mathrm{B} \subseteq \mathrm{X}$ be an IFOS. Then $\operatorname{int}(\mathrm{B})=\mathrm{B}$. By hypothesis $f(B)$ is an $I F \pi G \beta C S$ in $Y$. Since $Y$ is an IF $\pi \beta T 1 / 2$ space, $\mathrm{f}(\mathrm{B})$ is an IF $\beta C$ S in $Y$. This implies $\beta \mathrm{cl}(\mathrm{f}(\mathrm{B}))=\mathrm{f}(\mathrm{B})=$ $\mathrm{f}(\operatorname{int}(\mathrm{B})) \subseteq \mathrm{f}(\operatorname{int}(\beta \mathrm{cl}(\mathrm{B})))$.

(ii) can be proved easily by taking complement in (i).

Theorem 4.9: A mapping $\mathrm{f}:(\mathrm{X}, \tau) \rightarrow(\mathrm{Y}, \sigma)$ is an IFC $\pi \mathrm{G} \beta O M$ if $\mathrm{f}(\beta \mathrm{cl}(\mathrm{B})) \subseteq \operatorname{int}(\mathrm{f}(\mathrm{B}))$ for every IFS B in $\mathrm{X}$.

Proof: Let $\mathrm{B} \subseteq \mathrm{X}$ be an IFCS. Then $\mathrm{cl}(\mathrm{B})=\mathrm{B}$. Since every IFCS is an IF $\beta C S, \beta c l(B)=B$. Now by hypothesis, $f(B)=$ $\mathrm{f}(\beta \mathrm{cl}(\mathrm{B})) \subseteq \operatorname{int}(\mathrm{f}(\mathrm{B})) \subseteq \mathrm{f}(\mathrm{B})$. This implies $\mathrm{f}(\mathrm{B})$ is an IFOS in $Y$. Therefore $f(B)$ is an IF $\pi G \beta O S$ in $Y$. Hence $f$ is an
$\mathrm{IFC} \pi \mathrm{G} \beta \mathrm{OM}$.

Theorem 4.10: A mapping $\mathrm{f}:(\mathrm{X}, \tau) \rightarrow(\mathrm{Y}, \sigma)$ is an IFC $\pi \mathrm{G} \beta O M$, where $\mathrm{Y}$ is an IF $\pi \beta \mathrm{T} 1 / 2$ space if and only if $\mathrm{f}(\beta \mathrm{cl}(\mathrm{B})) \subseteq \beta \operatorname{int}(\mathrm{f}(\mathrm{cl}(\mathrm{B})))$ for every IFS B in $\mathrm{X}$.

Proof: Necessity: Let $\mathrm{B} \subseteq \mathrm{X}$ be an IFS. Then $\mathrm{cl}(\mathrm{B})$ is an IFCS in $\mathrm{X}$. By hypothesis $\mathrm{f}(\mathrm{cl}(\mathrm{B}))$ is an IF $\pi \mathrm{G} \beta \mathrm{OS}$ in $\mathrm{Y}$. Since $Y$ is an IF $\beta T 1 / 2$ space, $\mathrm{f}(\mathrm{cl}(\mathrm{B}))$ is an IFßOS in $\mathrm{Y}$. Therefore $\mathrm{f}(\beta \mathrm{cl}(\mathrm{B})) \subseteq \mathrm{f}(\mathrm{cl}(\mathrm{B}))=\beta \operatorname{int}(\mathrm{f}(\mathrm{cl}(\mathrm{B})))$.

Sufficiency: Let $\mathrm{B} \subseteq \mathrm{X}$ be an IFCS. Then $\mathrm{cl}(\mathrm{B})=\mathrm{B}$. By hypothesis, $\mathrm{f}(\beta \mathrm{cl}(\mathrm{B})) \subseteq \beta \operatorname{int}(\mathrm{f}(\mathrm{cl}(\mathrm{B})))=\beta \operatorname{int}(\mathrm{f}(\mathrm{B}))$. But $\beta \mathrm{cl}(\mathrm{B})=\mathrm{B}$. Therefore $\mathrm{f}(\mathrm{B})=\mathrm{f}(\beta \mathrm{cl}(\mathrm{B})) \subseteq \beta \operatorname{int}(\mathrm{f}(\mathrm{B}) \subseteq \mathrm{f}(\mathrm{B})$. This implies $\mathrm{f}(\mathrm{B})$ is an IF $\beta O S$ in $\mathrm{Y}$ and hence an IF $\pi \mathrm{G} \beta O S$ in $\mathrm{Y}$. Hence $\mathrm{f}$ is an IFC $\pi \mathrm{G} \beta O M$.

Theorem 4.11: An IFOM $\mathrm{f}:(\mathrm{X}, \tau) \rightarrow(\mathrm{Y}, \sigma)$ is an $\mathrm{IFC} \pi \mathrm{G} \beta O M$ if $\mathrm{IF} \pi \mathrm{G} \beta \mathrm{O}(\mathrm{Y})=\mathrm{IF} \pi \mathrm{G} \beta \mathrm{C}(\mathrm{Y})$.

Proof: Let $A \subseteq X$ be an IFOS. By hypothesis, $f(A)$ is an IFOS in $Y$ and hence is an IF $\pi G \beta O S$ in $Y$. Thus $f(A)$ is an $\mathrm{IF} \pi \mathrm{G} \beta \mathrm{CS}$ in $\mathrm{Y}$, since $\mathrm{IF} \pi \mathrm{G} \beta \mathrm{O}(\mathrm{Y})=\mathrm{IF} \pi \mathrm{G} \beta \mathrm{C}(\mathrm{Y})$. Therefore $\mathrm{f}$ is an IFC $\pi \mathrm{G} \beta O M$.

Definition 4.12: A mapping $\mathrm{f}:(\mathrm{X}, \tau) \rightarrow(\mathrm{Y}, \sigma)$ is said to be an intuitionistic fuzzy almost contra $\pi$ generalized $\beta$ open mapping (IFAC $\pi \mathrm{G} \beta O M$ for short) if $\mathrm{f}(\mathrm{A})$ is an IF $\pi \mathrm{G} \beta \mathrm{CS}$ in $\mathrm{Y}$ for every IFROS $\mathrm{A}$ in $\mathrm{X}$.

Example 4.13: Let $\mathrm{X}=\{\mathrm{a}, \mathrm{b}\}, \mathrm{Y}=\{\mathrm{u}, \mathrm{v}\}$ and $\mathrm{G} 1=\langle\mathrm{x},(0.4$ $0.2),(0.5,0.4\rangle, \mathrm{G} 2=\langle\mathrm{y},(0.5,0.3),(0.5,0.4)\rangle$. Then $\tau=\{0 \sim$, G1, 1 $\}$ and $\sigma=\{0 \sim, \mathrm{G} 2,1 \sim\}$ are IFTs on $\mathrm{X}$ and $\mathrm{Y}$ respectively. Define a mapping $\mathrm{f}:(\mathrm{X}, \tau) \rightarrow(\mathrm{Y}, \sigma)$ by $\mathrm{f}(\mathrm{a})=$ $\mathrm{u}$ and

$\mathrm{f}(\mathrm{b})=\mathrm{v}$. Then $\mathrm{f}$ is an IFAC $\pi \mathrm{G} \beta O M$.

Theorem 4.14: If $\mathrm{f}:(\mathrm{X}, \tau) \rightarrow(\mathrm{Y}, \sigma)$ is a bijective mapping, where $\mathrm{Y}$ is an IF $\pi \beta \mathrm{T} 1 / 2$ space, then the following conditions are equivalent:

(i) $\mathrm{f}$ is an IFAC $\pi \mathrm{G} \beta \mathrm{OM}$.

(ii) $\mathrm{f}(\mathrm{A}) \subseteq \mathrm{IF} \pi \mathrm{G} \beta \mathrm{O}(\mathrm{Y})$ for every $\mathrm{A} \in \mathrm{IFRC}(\mathrm{X})$.

(iii) $\mathrm{f}(\operatorname{int}(\mathrm{cl}(\mathrm{A}))) \beta \operatorname{IF} \pi \mathrm{G} \beta \mathrm{C}(\mathrm{Y})$ for every IFOS $\mathrm{A} \in \mathrm{X}$.

(iv) $\mathrm{f}(\mathrm{cl}(\operatorname{int}(\mathrm{A}))) \subseteq \mathrm{IF} \pi \mathrm{G} \beta \mathrm{O}(\mathrm{Y})$ for every IFCS $\mathrm{A} \in \mathrm{X}$.

Proof: (i) $\Rightarrow$ (ii) is obvious.

(i) $\Rightarrow$ (iii) Let A be any IFOS in X. Then $\operatorname{int}(\operatorname{cl}(\mathrm{A}))$ is an IFROS in $\mathrm{X}$. By hypothesis, $\mathrm{f}(\mathrm{int}(\mathrm{cl}(\mathrm{A})))$ is an IF $\pi \mathrm{G} \beta \mathrm{CS}$ in 
Y. Hence $\mathrm{f}(\operatorname{int}(\mathrm{cl}(\mathrm{A}))) \in \mathrm{IF} \pi \mathrm{G} \beta \mathrm{C}(\mathrm{Y})$.

(iii) $\Rightarrow$ (i) Let $\mathrm{A}$ be any IFROS in $\mathrm{X}$. Then $\mathrm{A}$ is an IFOS in $X$. By hypothesis, $\mathrm{f}(\operatorname{int}(\mathrm{cl}(\mathrm{A}))) \in \mathrm{IF} \pi \mathrm{G} \beta \mathrm{C}(\mathrm{Y})$.

That is $\mathrm{f}(\mathrm{A}) \in \operatorname{IF} \pi \mathrm{G} \beta(\mathrm{Y})$, since $\operatorname{int}(\operatorname{cl}(\mathrm{A}))=\mathrm{A}$. Hence $\mathrm{f}$ is an IFAC $\pi \mathrm{G} \beta \mathrm{OM}$.

(ii) $\Rightarrow$ (iv) is similar as (i) $\Rightarrow$ (iii).

Theorem 4.15: If $\mathrm{f}:(\mathrm{X}, \tau) \rightarrow(\mathrm{Y}, \sigma)$ is a mapping, where $\mathrm{X}$ is an IF $\beta T 1 / 2$ space, then the following are equivalent:

(i) $\mathrm{f}$ is an IFAC $\pi \mathrm{G} \beta$ continuous mapping .

(ii) $\mathrm{f}^{-1}(\mathrm{~A}) \in \operatorname{IF} \pi \mathrm{G} \beta \mathrm{O}(\mathrm{X})$ for every $\mathrm{A} \in \operatorname{IFRC}(\mathrm{Y})$

(iii) $\mathrm{f}^{-1}(\operatorname{int}(\operatorname{cl}(\mathrm{G}))) \in \mathrm{IF} \pi \mathrm{G} \beta \mathrm{C}(\mathrm{X})$ for every $\mathrm{IFOS} \mathrm{G} \subseteq \mathrm{Y}$

(iv) $\mathrm{f}^{-1}(\operatorname{cl}(\operatorname{int}(\mathrm{H}))) \in \mathrm{IF} \pi \mathrm{G} \beta \mathrm{O}(\mathrm{X})$ for every $\mathrm{IFCS} \mathrm{H} \subseteq \mathrm{Y}$

Proof: (i) $\Rightarrow$ (ii) Let $A$ be an IFRCS in Y. Then $A^{c}$ is an IFROS in $\mathrm{Y}$. By hypothesis, $\mathrm{f}^{-1}\left(\mathrm{~A}^{\mathrm{c}}\right)$ is an IF $\pi \mathrm{G} \beta \mathrm{CS}$ in $\mathrm{X}$. Therefore $\mathrm{f}^{-1}(\mathrm{~A})$ is an IF $\pi \mathrm{G} \beta \mathrm{OS}$ in $\mathrm{X}$. Therefore $\mathrm{f}^{-1}(\mathrm{~A})$ is an $\mathrm{IF} \pi \mathrm{G} \beta \mathrm{OS}$ in $\mathrm{X}$.

(i) $\Rightarrow$ (iii) Let $G$ be any IFOS in Y. Then $\operatorname{int}(\mathrm{cl}(\mathrm{G}))$ is an IFROS in Y. By hypothesis, $\mathrm{f}^{-1}(\operatorname{int}(\mathrm{cl}(\mathrm{G})))$ is an IF $\pi \mathrm{G} \beta \mathrm{CS}$ in $X$. Hence $\mathrm{f}^{-1}(\operatorname{int}(\mathrm{cl}(\mathrm{G}))) \in \operatorname{IF} \pi \mathrm{G} \beta \mathrm{C}(\mathrm{X})$.

(iii) $\Rightarrow$ (i) Let A be any IFROS in Y. Then A is an IFOS in Y. By hypothesis, we have $\mathrm{f}^{-1}(\operatorname{int}(\operatorname{cl}(\mathrm{A}))) \subseteq \mathrm{IF} \pi \mathrm{G} \beta \mathrm{C}(\mathrm{X})$. That is $\mathrm{f}^{-1}(A) \in \operatorname{IF} \pi \mathrm{G} \beta \mathrm{C}(\mathrm{X})$, since $\operatorname{int}(\operatorname{cl}(\mathrm{A}))=\mathrm{A}$. Hence $\mathrm{f}$ is an IFAC $\pi \mathrm{G} \beta$ continuous mapping.

(ii) $\Rightarrow$ (iv) is similar to (i) $\Rightarrow$ (iii).

Definition 4.16: A mapping $\mathrm{f}:(\mathrm{X}, \tau) \rightarrow(\mathrm{Y}, \sigma)$ is said to be an intuitionistic fuzzy contra $\mathrm{M} \pi \mathrm{G} \beta$ open mapping (IFCM $\pi \mathrm{G} \beta \mathrm{OM}$ ) if $\mathrm{f}(\mathrm{A})$ is an IF $\pi \mathrm{G} \beta \mathrm{CS}$ in $\mathrm{Y}$ for every $\mathrm{IF} \pi \mathrm{G} \beta \mathrm{OS} \mathrm{A}$ in $\mathrm{X}$.

Example 4.17: Let $\mathrm{X}=\{\mathrm{a}, \mathrm{b}\}, \mathrm{Y}=\{\mathrm{u}, \mathrm{v}\}$ and $\mathrm{G} 1=\langle\mathrm{x},(0.5$, $0.6),(0.4,0.3)\rangle, \mathrm{G} 2=\langle\mathrm{y},(0.2,0.3),(0.8,0.7)\rangle$. Then $\tau=$ $\{0 \sim, \mathrm{G} 1,1 \sim\}$ and $\sigma=\{0 \sim, \mathrm{G} 2,1 \sim\}$ are IFTs on $\mathrm{X}$ and $\mathrm{Y}$ respectively. Define a mapping

$\mathrm{f}:(\mathrm{X}, \tau) \rightarrow(\mathrm{Y}, \sigma)$ by $\mathrm{f}(\mathrm{a})=\mathrm{u}$ and $\mathrm{f}(\mathrm{b})=\mathrm{v}$. Then $\mathrm{f}$ is an IFCM $\pi \mathrm{G} \beta \mathrm{OM}$.

Theorem 4.18: Let $\mathrm{f}:(\mathrm{X}, \tau) \rightarrow(\mathrm{Y}, \sigma)$ be a bijective mapping. Then the following statements are equivalent:

(i) $\mathrm{f}$ is an IFCM $\pi \mathrm{G} \beta O \mathrm{OM}$, (ii) $f(A)$ is an IF $\pi G \beta O S$ in $Y$ for every IF $\pi G \beta C S$ A in $X$.

Proof: (i) $\Rightarrow$ (ii) Let $A$ be an IF $\pi G \beta C S$ in $X$. Then $A^{c}$ is an $\mathrm{IF} \pi \mathrm{G} \beta \mathrm{OS}$ in $\mathrm{X}$. By hypothesis, $\mathrm{f}\left(\mathrm{A}^{\mathrm{c}}\right)$ is an IF $\pi \mathrm{G} \beta C \mathrm{CS}$ in $\mathrm{Y}$. That is $f(A)^{c}$ is an $\operatorname{IF} \pi G \beta C S$ in $Y$. Hence $f(A)$ is an $\mathrm{IF} \pi \mathrm{G} \beta \mathrm{OS}$ in $\mathrm{Y}$.

(ii) $\Rightarrow$ (i) Let $A$ be an IF $\pi G \beta O S$ in $X$. Then $A^{c}$ is an $\mathrm{IF} \pi \mathrm{G} \beta \mathrm{CS}$ in $\mathrm{X}$. By hypothesis, $\mathrm{f}\left(\mathrm{A}^{\mathrm{c}}\right)$ is an IF $\pi \mathrm{G} \beta O \mathrm{OS}$ in $\mathrm{Y}$.

Hence $\mathrm{f}(\mathrm{A})$ is an IF $\pi \mathrm{G} \beta C$ S in $\mathrm{Y}$. Thus $\mathrm{f}$ is an IFCM $\pi \mathrm{G} \beta \mathrm{OM}$.

Theorem 4.19: Every IFCM $\pi \mathrm{G} \beta O M$ is an IFC $\pi \mathrm{G} \beta O M$ but not conversely.

Proof: let $\mathrm{f}:(\mathrm{X}, \tau) \rightarrow(\mathrm{Y}, \sigma)$ be an IFCM $\pi \mathrm{G} \beta \mathrm{OM}$, and $\mathrm{A} \subseteq$ $\mathrm{X}$ be an IFOS. Then $\mathrm{A}$ is an IF $\pi \mathrm{G} \beta \mathrm{OS}$ in $\mathrm{X}$. By hypothesis, $\mathrm{f}(\mathrm{A})$ is an $\mathrm{IF} \pi \mathrm{G} \beta \mathrm{CS}$ in $\mathrm{Y}$. Hence $\mathrm{f}$ is an IFC $\pi \mathrm{G} \beta O M$.

Example 4.20 Let $\mathrm{X}=\{\mathrm{a}, \mathrm{b}\}, \mathrm{Y}=\{\mathrm{u}, \mathrm{v}\}$ and $\mathrm{G} 1=\langle\mathrm{x},(0 \mathrm{a}$, $0.3 \mathrm{~b}),(0.5 \mathrm{a}, 0.4 \mathrm{~b})\rangle, \mathrm{G} 2=\langle\mathrm{y},(0.2 \mathrm{u}, 0.4 \mathrm{v}),(0.5 \mathrm{u}, 0.4 \mathrm{v})\rangle \mathrm{G} 3=\langle$ $\mathrm{y},(0.1 \mathrm{u}, 0.3 \mathrm{v}),(0.3 \mathrm{u}, 0.4 \mathrm{v})\rangle, \mathrm{G} 4=\langle\mathrm{y},(0.1 \mathrm{u}, 0.3 \mathrm{v}),(0.5 \mathrm{u}$, $0.4 \mathrm{v})\rangle, \mathrm{G} 5=\langle\mathrm{y},(0.2 \mathrm{u}, 0.4 \mathrm{v}),(0.3 \mathrm{u}, 0.4 \mathrm{v})\rangle$ and $\mathrm{G} 6=\langle\mathrm{y}$, $(0.4 \mathrm{u}, 0.4 \mathrm{v}),(0.3 \mathrm{u}, 0.4 \mathrm{v})\rangle$. Then $\tau=\{0 \sim, \mathrm{G} 1,1 \sim\}$ and $\sigma=$ $\{0 \sim, \mathrm{G} 2, \mathrm{G} 3, \mathrm{G} 4, \mathrm{G} 5, \mathrm{G} 6,1 \sim\}$ are IFTs on $\mathrm{X}$ and $\mathrm{Y}$ respectively. Define a mapping $\mathrm{f}:(\mathrm{X}, \tau) \quad(\mathrm{Y}$,$) by \mathrm{f}(\mathrm{a})=\mathrm{u}$ and $\mathrm{f}(\mathrm{b})=\mathrm{v}$. Then $\mathrm{f}$ is an IFC $\pi \mathrm{G} \beta O M$ but not an IFCM $\pi \mathrm{G} \beta O M$, since $A=x,(0 a, 0.3 b),(0.5 a, 0.4 b)$ is an IFCM $\pi \mathrm{G} \beta O S$ in $\mathrm{X}$ but $\mathrm{f}(\mathrm{A})=\mathrm{y},(0 \mathrm{u}, 0.3 \mathrm{v}),(0.5 \mathrm{u}, 0.4 \mathrm{v})$ is not an $\mathrm{IF} \pi \mathrm{G} \beta \mathrm{CS}$ in $\mathrm{Y}$.

Theorem 4.21 (i) If $\mathrm{f}:(\mathrm{X}, \tau) \rightarrow(\mathrm{Y}, \sigma)$ is an IFOM and $\mathrm{g}$ : $(\mathrm{Y}, \sigma) \rightarrow(\mathrm{Z}, \eta)$ be an IFC $\pi \mathrm{G} \beta O M$, then $\mathrm{g}_{\mathrm{o}} \mathrm{f}$ is an $\mathrm{IFC} \pi \mathrm{G} \beta \mathrm{OM}$.

(ii) If $\mathrm{f}:(\mathrm{X}, \tau) \rightarrow(\mathrm{Y}, \sigma)$ is an IFC $\pi \mathrm{G} \beta \mathrm{OM}$ and $\mathrm{g}:(\mathrm{Y}, \sigma) \rightarrow$ $(\mathrm{Z}, \eta)$ is an IFM $\pi \mathrm{G} \beta C M$, then $\mathrm{g}_{\mathrm{o}} \mathrm{f}$ is an IFC $\pi \mathrm{G} \beta \mathrm{OM}$.

(iii) If $\mathrm{f}:(\mathrm{X}, \tau) \rightarrow(\mathrm{Y}, \sigma)$ is an $\mathrm{IF} \pi \mathrm{G} \beta \mathrm{OM}$ and $\mathrm{g}:(\mathrm{Y}, \sigma)$ $\rightarrow(\mathrm{Z}, \eta)$ is an IFCM $\pi \mathrm{G} \beta O M$, then $\mathrm{g}_{0} \mathrm{f}$ is an IFC $\pi \mathrm{G} \beta O M$.

(iv) If $\mathrm{f}:(\mathrm{X}, \tau) \rightarrow(\mathrm{Y}, \sigma)$ is an IFC $\pi \mathrm{G} \beta \mathrm{OM}$ and $\mathrm{g}:(\mathrm{Y}, \sigma) \rightarrow$ $(Z, \eta)$ is an IFCM $\pi \mathrm{G} \beta O M$, then $\mathrm{g}_{\mathrm{o}} \mathrm{f}:(\mathrm{X}, \tau) \rightarrow(\mathrm{Z}, \eta)$ is an $\mathrm{IF} \pi \mathrm{G} \beta \mathrm{OM}$.

Proof: (i) Let A be an IFOS in X. Then $\mathrm{f}(\mathrm{A})$ is an IFOS in $Y$. Therefore $g(f(A))$ is an IF $\pi G \beta C S$ in $Z$. Hence $g \square$ is an $\mathrm{IFC} \pi \mathrm{G} \beta \mathrm{OM}$.

(ii) Let $A$ be an IFOS in $X$. Then $\mathrm{f}(\mathrm{A})$ is an IF $\pi \mathrm{G} \beta \mathrm{CS}$ in $\mathrm{Y}$. Therefore $\mathrm{g}(\mathrm{f}(\mathrm{A}))$ is an $\mathrm{IF} \pi \mathrm{G} \beta \mathrm{CS}$ in $\mathrm{Z}$. Hence $\mathrm{g}_{\square} \mathrm{f}$ is an $\mathrm{IFC} \pi \mathrm{G} \beta \mathrm{OM}$. 
(iii) Let $A$ be an IFOS in $X$. Then $f(A)$ is an IF $\pi g \beta O S$ in $Y$. Therefore $\mathrm{g}(\mathrm{f}(\mathrm{A}))$ is an $\mathrm{IF} \pi \mathrm{G} \beta C S$ in $\mathrm{Z}$. Hence $\mathrm{g}_{\square} \mathrm{f}$ is an IFC $\pi \mathrm{G} \beta \mathrm{GOM}$.

(iv) Let $A$ be an IFOS in $X$. Then $f(A)$ is an IF $\pi G \beta C$ S in $Y$, since $\mathrm{f}$ is an IFC $\pi \mathrm{G} \beta O \mathrm{OM}$. Since $\mathrm{g}$ is an IFCM $\pi \mathrm{G} \beta \mathrm{OM}$, $\mathrm{g}(\mathrm{f}(\mathrm{A}))$ is an IF $\pi \mathrm{G} \beta \mathrm{OS}$ in $\mathrm{Z}$. Therefore $\mathrm{g}_{\square} \mathrm{f}$ is an IF $\pi \mathrm{G} \beta \mathrm{OM}$.

Theorem 4.22: If $\mathrm{f}:(\mathrm{X}, \tau) \rightarrow(\mathrm{Y}, \sigma)$ is an IFCM $\pi \mathrm{G} \beta \mathrm{OM}$, then for any $\operatorname{IF} \pi \mathrm{G} \beta \mathrm{CS} A$ in $\mathrm{X}$ and for any $\operatorname{IFP} \mathrm{p}(\alpha, \beta) \in \mathrm{Y}$, if $\mathrm{f}^{-1}(\mathrm{p}(\alpha, \beta)) \mathrm{q} A$, then $\mathrm{p}(\alpha, \beta)_{\mathrm{q}} \pi \mathrm{G} \beta \operatorname{int}(\mathrm{f}(\mathrm{A}))$.

Proof: Let $A \subseteq X$ be an $I F \pi G \beta C S$ and let $p(\alpha, \beta) \in Y$. Assume that $\mathrm{f}^{-1}(\mathrm{p}(\alpha, \beta)){ }_{q} \mathrm{~A}$. Then $\mathrm{p}(\alpha, \beta)_{q} \mathrm{f}(\mathrm{A})$. By hypothesis, $\mathrm{f}(\mathrm{A})$ is an $\mathrm{IF} \pi \mathrm{G} \beta \mathrm{OS}$ in $\mathrm{Y}$. This implies $\pi G \beta \operatorname{int}(f(A))=f(A)$. Hence $p(\alpha, \beta){ }_{q} \pi G \beta \operatorname{int}(f(A))$.

Theorem 4.23: If $\mathrm{f}:(\mathrm{X}, \tau) \rightarrow(\mathrm{Y}, \sigma)$ is an $\operatorname{IFC} \pi \mathrm{G} \beta$ closed mapping and $\mathrm{Y}$ is an IF $\pi \beta T 1 / 2$ space, then $\mathrm{f}(\mathrm{A})$ is an IFGOS in $\mathrm{Y}$ for every IFCS A in $\mathrm{X}$.

Proof: Let $\mathrm{f}:(\mathrm{X}, \tau) \rightarrow(\mathrm{Y}, \sigma)$ be an IFC $\pi \mathrm{G} \beta$ closed mapping and let $\mathrm{A}$ be an IFCS in $\mathrm{X}$. Then by hypothesis $\mathrm{f}(\mathrm{A})$ is an IF $\pi$ G $\beta O S$ in $Y$. Since $Y$ is an IF $\pi \beta T 1 / 2$ space, $f(A)$ is an IFGOS in Y.

\section{REFERENCES :}

[1] Atanassov,K., Intuitionistic fuzzy sets, Fuzzy Sets and Systems, 1986,87-96.

[2] Chang, C., Fuzzy topological spaces, J. Math. Anal.Appl.,1968,182190.

[3] Coker,D., An introduction to intuitionistic fuzzy topological space, Fuzzy sets and systems, 1997,81-89.

[4] E.Ekici and B.Krsteska, Intuitionistic fuzzy contra strong pre- continuity, Facta Univ. Ser. Math. Inform., 2007, 273-284

[5] Gurcay,H . ,Coker,D., and Haydar,Es .A., On fuzzy continuity inintuitionistic fuzzy topological spaces, mathematics, 1997, 365-378.

[6] S.Jafari and T.Noiri and- " Properties of $\beta$-Connected Spaces " , Acta Math. Hung., 101(2003), pp. 227-236.

[7] S.Jothimani and T.Jenitha Premalatha., Intuitionistic fuzzy $\pi$ generalized beta closed mappings -Math . Sci.Lett 6.No1,1$7(2017)$

[8] S.Jothimani and T.Jenitha Premalatha., On Almost and Contra $\pi \mathrm{G} \beta$ Continuous Mappings in Intuitionisics fuzzy topological spaces.- submitted

[9] Joung Kon Jeon, Young Bae Jun, and Jin Han Park, Intuitionistic fuzzy alpha-continuity and intuitionistic fuzzy pre continuity, International Journal of Mathematics and Mathematical Sciences, 2005, 3091-3101.

[10] Santhi, R. and Jayanthi, D., Intuitionistic fuzzy generalized semipre closed mappings-"Notes on IFS", Volume 16 (2010) Number 3 , pages $28-39$.

[11] Thakur, S.S and RekhaChaturvedi, Regular generalized closed sets in intuitionistic fuzzy topological spaces Universitatea Din Bacau Studii Si Cercertar Stiintifice vol 6 pp 257-272.

[12] Young Bae Jun and Seok-Zun Song, Intuitionistic fuzzy beta open sets and Intuitionistic beta continuous mappings Jour.of Appl. Math \& computing,2005,467-474.

[13] Zadeh, L. A., Fuzzy sets, Information and control, 1965,338-35.

\section{AUTHORS PROFILE :}

Dr. S.Jothimani, Assistant Professor in the Department of Mathematics, Government Arts College, Coimbatore. She has completed her research in the field of Fluid Dynamics, in the year 2003, from Bharathiar University. She has published research papers in 13 International Journals in the field of Fluid dynamics, and more than 12 papers in the field of Topology. She has 18 years of teaching experience and she is guiding 5 research scholars.

T. Jenitha Premalatha, Associate Professor in the Department of Mathematics, TIPS College of Arts and Science,Coimbatore. Her research interest is in the area of Topology, She has published in 12 International Journals and presented a paper in International Conference. She has 18 years of teaching experience. 